\title{
The saprotrophic Pleurotus ostreatus species complex: late Eocene origin in East Asia, multiple dispersal, and complex speciation
}

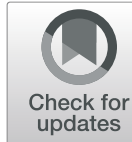

Jing Li ${ }^{1,2,3}$, Li-Hong Han ${ }^{4}$, Xiao-Bin Liu ${ }^{1,2}$, Zhi-Wei Zhao ${ }^{3^{*}}$ and Zhu L. Yang ${ }^{1,2^{*}}$

\begin{abstract}
The Pleurotus ostreatus species complex is saprotrophic and of significant economic and ecological importance. However, species delimitation has long been problematic because of phenotypic plasticity and morphological stasis. In addition, the evolutionary history is poorly understood due to limited sampling and insufficient gene fragments employed for phylogenetic analyses. Comprehensive sampling from Asia, Europe, North and South America and Africa was used to run phylogenetic analyses of the $P$. ostreatus species complex based on 40 nuclear single-copy orthologous genes using maximum likelihood and Bayesian inference analyses. Here, we present a robust phylogeny of the $P$. ostreatus species complex, fully resolved from the deepest nodes to species level. The $P$. ostreatus species complex was strongly supported as monophyletic, and 20 phylogenetic species were recognized, with seven putatively new species. Data from our molecular clock analyses suggested that divergence of the genus Pleurotus probably occurred in the late Jurassic, while the most recent common ancestor of the P. ostreatus species complex diversified about $39 \mathrm{Ma}$ in East Asia. Species of the P. ostreatus complex might migrate from the East Asia into North America across the North Atlantic Land Bridge or the Bering Land Bridge at different times during the late Oligocene, late Miocene and late Pliocene, and then diversified in the Old and New Worlds simultaneously through multiple dispersal and vicariance events. The dispersal from East Asia to South America in the middle Oligocene was probably achieved by a long-distance dispersal event. Intensification of aridity and climate cooling events in the late Miocene and Quaternary glacial cycling probably had a significant influence on diversification patterns of the complex. The disjunctions among East Asia, Europe, North America and Africa within Clade Ilc are hypothesized to be a result of allopatric speciation. Substrate transitions to Apiaceae probably occurred no earlier than $6 \mathrm{Ma}$. Biogeographic analyses suggested that the global cooling of the late Eocene, intensification of aridity caused by rapid uplift of the QTP and retreat of the Tethys Sea in the late Miocene, climate cooling events in Quaternary glacial cycling, and substrate transitions have contributed jointly to diversification of the species complex.
\end{abstract}

Keywords: Illumina MiSeq, Molecular phylogeny, Species recognition, East Asian origin, Diversification, Saprotrophic mushrooms

\footnotetext{
* Correspondence: fungi@mail.kib.ac.cn; zhaozhw@ynu.edu.cn

${ }^{1}$ CAS Key Laboratory for Plant Diversity and Biogeography of East Asia,

Kunming Institute of Botany, Chinese Academy of Science, Kunming 650201,

Yunnan, China

${ }^{3}$ State Key Laboratory of Conservation and Utilization for Bioresources in

Yunnan, Yunnan University, Kunming 650091, Yunnan, China

Full list of author information is available at the end of the article
}

(c) The Author(s). 2020 Open Access This article is licensed under a Creative Commons Attribution 4.0 International License, which permits use, sharing, adaptation, distribution and reproduction in any medium or format, as long as you give

appropriate credit to the original author(s) and the source, provide a link to the Creative Commons licence, and indicate if changes were made. The images or other third party material in this article are included in the article's Creative Commons licence, unless indicated otherwise in a credit line to the material. If material is not included in the article's Creative Commons licence and your intended use is not permitted by statutory regulation or exceeds the permitted use, you will need to obtain permission directly from the copyright holder. To view a copy of this licence, visit http://creativecommons.org/licenses/by/4.0/. 


\section{INTRODUCTION}

The origin and evolution of species is one of the most important issues in biological research (Seehausen et al. 2014; Wiens 2004), and biogeographic studies aim to reconstruct the origin, speciation and distribution patterns of organisms (AI-Tanlimi et al. 2003; Schluter 2000). To date, there have been a number of biogeographicalevolutionary studies in higher plants and animals (Carranza and Arnold 2004; Conti et al. 2002; Dobigny et al. 2005; Sanmartín and Ronquist 2004; Yi et al. 2015). Mushrooms, or macrofungi, represent one of the most diverse groups of organisms in the world, but have been the subject only very limited biogeographical analysis, perhaps because of limited morphological species recognition (Taylor et al. 2006), incomplete sampling in many regions of the world (Schmit \& Mueller 2007), the scanty fungal fossil record (Taylor and Berbee 2006), and the view that mushrooms are able to overcome geographic barriers by virtue of their airborne spores (Hibbett 2001; Vilgalys and Sun 1994a). It's worth noting that the limited numbers of molecular phylogenetic studies involving mushrooms have gained new insights into the historical dynamics of macrofungi and show that macrofungi provide interesting subjects for biogeographic studies (Coetzee et al. 2000; James et al. 2001; Lumbsch et al. 2008; Nagy et al. 2011).

Molecular-based biogeographic studies of macrofungi have mainly focused on ectomycorrhizal fungi (EMF) with wide geographic distributions (Cai et al. 2014; Feng et al. 2012; Han et al. 2018; Hibbett and Matheny 2009; Hosaka et al. 2008; Sánchez-Ramríez et al. 2015; Truong et al. 2017). Saprotrophic fungi (SPF) have a worldwide distribution and also play critical roles in ecosystem function, soil health, and human and animal nutrition (Austin et al. 2004; McGonigle 1995; Rayner and Boddy 1988; Wolfe et al. 2012). The biogeographic structures of various saprotrophic agarics in the Northern Hemisphere or with broad geographical distribution have recently started to be uncovered (Hibbett et al. 1998; Methven et al. 2000). However, few of the above studies specifically included SPF from both the Southern and Northern Hemispheres (Carlsen et al. 2011; James et al. 1999) and even fewer have attempted molecular clock dating and diversification methods to investigate the date of origin and historical diversification (Moncalvo and Buchanan 2008; Qin et al. 2018; Skrede et al. 2011). In general, the spatio-temporal dynamics and mechanisms of distribution and diversification of global saprotrophic fungal species are poorly understood.

The Pleurotus ostreatus species complex harbors most of the species of Pleurotus sect. Pleurotus as defined by Singer (1986), all of which possess a monomitic hyphal system. Specifically, $P$. ostreatus (Jacq.) P. Kumm., $P$. pulmonarius (Fr.) Quél. and P. placentodes (Berk.) Sacc. and their allies belong to the complex. Because of its nutritional and medical properties, as well as diverse biotechnological applications, the $P$. ostreatus species complex is one of the three most actively cultivated mushroom species in the world (Baker et al. 2018; Cardwell et al. 2018; Golak-Siwulska et al. 2018). As commonly found saprotrophic mushrooms, species within the $P$. ostreatus complex constitute essential components in forest and grassland ecosystems because of their roles as decomposers of a large array of lignocellulosic substrates, such as deciduous trees (Kay and Vilgalys 1992; Petersen and Krisai-Greilhuber 1996), coniferous trees (Petersen and Hughes 1997; Vilgalys et al. 1993), as well as herbs in the Apiaceae family (Zervakis et al. 2014). These fungi have also adapted to a wide variety of environments, ranging from mesic to semiarid conditions and temperate forest to subalpine.

Because this is an economically and ecologically important group, species diversity in the $P$. ostreatus species complex has been estimated using traditional morphological criteria and mating incompatibility tests (Hilber 1982; Petersen and Hughes 1993; Singer 1986; Vilgalys et al. 1993; Zervakis and Balis 1996; Zervakis et al. 2014). Based on morphological features and mating compatibility, geographic distribution patterns and host ranges of the $P$. ostreatus species complex in Europe and North America have been elucidated (Vilgalys et al. 1993). An interesting study on the biogeography of the whole genus Pleurotus has suggested an ancient origin for some intersterile groups with worldwide distributions, while other intersterile groups in the Northern Hemisphere underwent more recent radiation and allopatric speciation (Vilgalys and Sun 1994b). Although a series of taxonomic and phylogenetic studies based on limited molecular markers have been published recently (Avin et al. 2014; Gao et al. 2008a; He et al. 2016; Kawai et al. 2008; Li et al. 2017; Thorn et al. 2000; Vilgalys et al. 1993; Zhao et al. 2016b; Zheng et al. 2006), a deep understanding of the diversity within this group is still lacking.

The advent of next-generation sequencing (NGS) has changed history diversification and molecular phylogenetic studies (Binder et al. 2013; Egan et al. 2012; McCormack et al. 2011; Yu et al. 2017). Nuclear single-copy orthologous genes have been demonstrated to be promising molecular markers for phylogenetic and evolutionary inferences (Sato et al. 2017; Sato and Toju 2019). We selected the $P$. ostreatus species complex to avoid incomplete taxon sampling, which often occurs during the analysis of large clades and could introduce serious biases into the estimation of the diversification rates (Brock et al. 2011; Rabosky 2010; Sato et al. 2017).

Deeper insight into phylogeny, species diversity, and diversification of the $P$. ostreatus species complex should 
be achieved by the analyses of multiple nuclear singlecopy orthologous sequences in combination with appropriate models of sequence evolution. The main objectives of this study are: (1) to reconstruct a well-resolved molecular phylogeny with comprehensive taxon sampling for the P. ostreatus species complex, based on multiple single-copy nuclear markers, using next generation sequencing; (2) to determine times of molecular divergence events within the $P$. ostreatus species complex and its major lineages, using phylogenetic analyses at the species complex and species levels; and (3) to reconstruct the geographic origins, the history of biogeographic diversification and the potential migration routes of the $P$. ostreatus species complex, based on paleontological evidence, palaeoclimatic records and estimated divergence times for the lineages within the complex.

\section{MATERIALS AND METHODS}

Screening of taxa used in the phylogenetic analysis for a large dataset

A total of 51 specimens of Pleurotus and Hohenbuehelia Schulzer (as an outgroup) were included in this study (Table 1). Specific information on voucher specimens and strains, including GenBank accession numbers, geographical locations, and substrates is in Table 1. Species belonging to Pleurotus have been reported from the temperate areas of East and West Asia, North and South America, Europe, Africa and the tropical areas of Southeast Asia (Albertó et al. 2002; Petersen and Hughes 1997; Petersen and Krisai-Greilhuber 1999; Vilgalys et al. 1993; Vilgalys and Sun 1994b; Zervakis and Balis 1996; Zervakis et al. 2004, 2014), whereas those belonging to Hohenbuehelia has been reported as the allied group of Pleurotus (Gao et al. 2008b; Li and Yao 2004; Li et al. 2017; Menolli Jr. et al. 2014; Singer 1986; Thorn et al. 2000). Most mushrooms analyzed here were chosen to cover as much of the known distribution range of the $P$. ostreatus species complex in the world as possible. Voucher specimens and strains for these samples are kept in the Herbarium of Cryptogams, Kunming Institute of Botany of the Chinese Academy of Sciences (HKAS), China Center for Mushroom Spawn Standards and Control (CCMSSC), the Herbarium of the Laboratory of the General and Agricultural University of Athens (ACAM), and the Westerdijk Fungal Biodiversity Institute (CBS).

Total DNA was isolated from the mycelia or specimen using the cetyltrimethyl ammonium bromide (CTAB) method (Doyle and Doyle 1987). The quality of the DNA was evaluated on agarose gels, and the concentrations of DNA were determined using an ND-2000 spectrophotometer (NanoDrop Technologies, Wilmington, DE, USA). The final DNA concentrations were adjusted to $25 \mathrm{ng} / \mathrm{L}$ and they were stored at $-20^{\circ} \mathrm{C}$ until use.
Selection of nuclear single-copy orthologous genes Amino acid sequences of single-copy genes from Phanerochaete chrysosporium Burds. (Phanerochaetaceae/ Polyporales/Agaricomycetes) were downloaded from the FUNYBASE database of fungal nuclear single-copy orthologous gene sequences, and the PCR primers that amplify single-copy genes of Agaricomycetes were designed by Sato et al. (2017). To screen for PCR amplification rate, 96 markers from their study with the expected product size ranging from 280 to $450 \mathrm{bp}$ were initially tested and screened against ten diverse specimens taken from different species within the $P$. ostreatus species complex recognized by previous studies based on morphological characteristics and molecular analyses (Bao et al. 2004; Hilber 1982; Li et al. 2017; Liu et al. 2015, 2016; Singer 1986; Zervakis et al. 2014; Zhao et al. 2016a, 2016b). The amplification reactions were performed in an ABI 2720 Thermal Cycler or a SimpliAmp Thermal Cycler (Applied Biosystems, Foster City, CA, USA) with the following protocol: one cycle at $94{ }^{\circ} \mathrm{C}$ for $3 \mathrm{~min}$; followed by 35 cycles at $94{ }^{\circ} \mathrm{C}$ for $30 \mathrm{~s}$, an annealing step at 50,52 or $54^{\circ} \mathrm{C}$ for $30 \mathrm{~s}, 72{ }^{\circ} \mathrm{C}$ for $1 \mathrm{~min}$; and a final extension step of $72{ }^{\circ} \mathrm{C}$ for $7 \mathrm{~min}$. During marker screening, priority was given to single-copy markers with PCR amplification rate of greater than $80 \%$. The primer sets for the 50 markers with greatest PCR amplification rates and single strong bands were modified for further experiments (Additional file 1).

\section{Sequencing of nuclear single-copy orthologous genes}

For next-generation sequencing, specimens were selected from each of the provisionally putative species of Pleurotus and Hohenbuehelia. A two-step PCR was performed for these representative samples followed by Sato et al. (2017). The PCR products were quantified using a Qubit 4 fluorometer (Invitrogen Corporation, California, USA), following which the concentrations of the PCR products were normalized. The adjusted PCR products were pooled, following which amplicons of length 450$600 \mathrm{bp}$ were excised and extracted using a Zymo DNA Clean \& Concentrator-5 and Zymoclean Gel DNA Recovery Kit (Zymo Research Corporation, Irvine City, CA, USA). The amplicon library was sequenced using paired-end sequencing on a MiSeq platform using a MiSeq v.3 Reagent Kit according to the manufacturer's instructions.

\section{Bioinformatic analyses}

BCL2FASTQ v.1.8.4 (Illumina, San Diego, CA, USA) was used to convert the base calls into forward, index1, index 2 and reverse FASTQ files. In order to obtain more accurate and reliable results in subsequent bioinformatics analysis, the raw data was pre-processed using an inhouse procedure as following: 1) Sequence reads not 
Table 1 List of specimens used to infer the phylogeny of Pleurotus ostreatus species complex

\begin{tabular}{|c|c|c|c|c|c|}
\hline \multirow[t]{2}{*}{ Taxon } & \multirow[t]{2}{*}{ Specimen } & \multirow[t]{2}{*}{ Locality } & \multirow[t]{2}{*}{ Substrate } & \multicolumn{2}{|c|}{ GenBank accession numbers } \\
\hline & & & & ITS & RPB2 \\
\hline Pleurotus abalonus & HKAS81197"a & Yunnan, China & Quercus sp. & MN546043 & MT138447 \\
\hline \multirow[t]{2}{*}{ P. abieticola } & HKAS89521 a & Sichuan, China & Picea sp. & MN546039 & - \\
\hline & HKAS89541 & Gansu, China & Picea sp. & MN546040 & MT138444 \\
\hline P. albidus & CBS119924 & Argentina & Quercus palustris & MN546041 & MT138443 \\
\hline \multirow[t]{2}{*}{ P. citrinopileatus } & HKAS93365 & Jilin, China & hardwood & MN546044 & MT138448 \\
\hline & HKAS94429 & Jilin, China & Populus sp. & - & MT138449 \\
\hline \multirow[t]{2}{*}{ P. cystidiosus } & HKAS106470 & Hunan, China & - & MN546042 & MT138446 \\
\hline & HKAS97644 & Yunnan, China & - & - & MT138445 \\
\hline \multirow[t]{2}{*}{ P. djamor } & HKAS94069 & Sri Lanka & - & KX061789 & - \\
\hline & HKAS94070 & Sri Lanka & - & MN546045 & - \\
\hline P. dryinus & HKAS94448 & Finland & - & MN546046 & - \\
\hline P. eryngii var. elaeoselini & $\mathrm{PN} 13^{\mathrm{a}}$ & Italy & Elaeoselinum asclepium & KF743831 & MT138430 \\
\hline \multirow[t]{2}{*}{ P. eryngii. var. eryngii } & CCMSSC00692 & Spain & Eryngium sp. & KX836357 & KX870362 \\
\hline & CCMSSC00467 & Italy & Eryngium sp. & - & MT138431 \\
\hline \multirow[t]{4}{*}{ P. eryngii var. ferulae } & $\operatorname{cCMSSC} 04223^{\mathrm{a}}$ & Italy & Ferula communis & KU612927 & MH374115 \\
\hline & CCMSSC00647 & Netherlands & Ferula communis & KU612924 & MH473116 \\
\hline & CCMSSC03175 & Xinjiang, China & Ferula communis & KU612920 & MH374117 \\
\hline & CCMSSC03217 & Xinjiang, China & Ferula communis & KU612916 & - \\
\hline P. ferulaginis & $\mathrm{HIK} 133^{\mathrm{a}}$ & Italy & Ferulago campestris & KF743826 & - \\
\hline P. fossulatus & $\mathrm{HIK} 127^{\mathrm{a}}$ & Armenia & Prangos ferulacea & HM998828 & - \\
\hline \multirow[t]{2}{*}{ P. nebrodensis } & CCMSSC04220 & Netherlands & Prangos ferulacea & KU612942 & - \\
\hline & CCMSSC00646 & Netherlands & Prangos ferulacea & KU612943 & KX870371 \\
\hline P. opuntiae & CBS102543 & Mexico & - & MN546047 & MT138450 \\
\hline \multirow[t]{3}{*}{ P. ostreatus } & HKAS84903 ${ }^{a}$ & Germany & Fagus sp. & KP867913 & KP867874 \\
\hline & CCMSSC00338 & Germany & Fagus sylvatica & KX836103 & KX870204 \\
\hline & HKAS93337 & France & Sabina chinensis & - & MT138429 \\
\hline \multirow[t]{4}{*}{ P. placentodes } & HKAS94410 a & Tibet, China & - & KX836665 & - \\
\hline & HKAS57781 & Yunnan, China & Picea sp. & KR827694 & KR827698 \\
\hline & YAASM3153 & Yunnan, China & - & - & KX870444 \\
\hline & YAASM2083 & Yunnan, China & - & - & KX870443 \\
\hline \multirow[t]{2}{*}{ P. populinus } & CBS109622 & USA & - & MN546031 & MT138442 \\
\hline & CBS666.85 & Canada & Populus sp. & MN546032 & MT138441 \\
\hline \multirow[t]{2}{*}{ P. pulmonarius } & HKAS56524 & Germany & Fagus sylvatica & MN546036 & - \\
\hline & CCMSSC00500 & Greece & - & KU612947 & MT138435 \\
\hline \multirow[t]{2}{*}{ P. tuoliensis } & CCMSSC03105 & Xinjiang, China & Ferula sp. & KU612906 & MH374113 \\
\hline & CCMSSC03212 & Xinjiang, China & Ferula sp. & KU612908 & MH374112 \\
\hline \multirow[t]{2}{*}{ Pleurotus sp. 1} & HKAS106471(Kejia1) & Hebei, China & - & KX836252 & KX870271 \\
\hline & HKAS106472(Pinggu2026) a & Hebei, China & - & KX836264 & KX870223 \\
\hline \multirow[t]{2}{*}{ Pleurotus sp. 2} & CCMSSC00324 & Japan & - & KX836142 & KX870232 \\
\hline & HKAS106473(YAASM2072) $^{a}$ & Yunnan, China & Betula sp. & KX836134 & KX870243 \\
\hline \multirow[t]{3}{*}{ Pleurotus sp. 3} & HKAS93372 & USA & Quercus sp. & MN546030 & MT138434 \\
\hline & HKAS106474(ZP742) ${ }^{a}$ & Canada & - & KX836193 & KX870345 \\
\hline & CBS195.92 & USA & _- & MN546028 & MT138433 \\
\hline
\end{tabular}


Table 1 List of specimens used to infer the phylogeny of Pleurotus ostreatus species complex (Continued)

\begin{tabular}{|c|c|c|c|c|c|}
\hline \multirow[t]{2}{*}{ Taxon } & \multirow[t]{2}{*}{ Specimen } & \multirow[t]{2}{*}{ Locality } & \multirow[t]{2}{*}{ Substrate } & \multicolumn{2}{|c|}{ GenBank accession numbers } \\
\hline & & & & ITS & $R P B 2$ \\
\hline Pleurotus sp. 4 & CCMSSC00346 ${ }^{\mathrm{a}}$ & Jilin, China & - & MN546029 & MT138432 \\
\hline \multirow[t]{2}{*}{ Pleurotus sp. 5} & HKAS92312 & Hubei, China & Fagaceae & KX836303 & KX870433 \\
\hline & HKAS91310 & Jilin, China & Fagaceae & KX836300 & KX870384 \\
\hline \multirow[t]{2}{*}{ Pleurotus sp. 6} & HKAS94322 $2^{a}$ & Canada & - & MN546037 & MT138439 \\
\hline & HKAS94336 & Canada & - & MN546038 & MT138440 \\
\hline \multirow[t]{3}{*}{ Pleurotus sp. 7} & HKAS94249 & Benin & Monotes kerstingii & MN546033 & MT138437 \\
\hline & HKAS94228 & Benin & Nauclea sp. & MN546034 & MT138436 \\
\hline & HKAS93854 & Benin & Monotes kerstingii & MN546035 & MT138438 \\
\hline H. portegna & HKAS74040 & Yunnan, China & - & KY426797 & - \\
\hline H. unguicularis & HKAS90443 & Yunnan, China & - & MN546048 & - \\
\hline
\end{tabular}

Samples used for diversification analyses and ancestral state reconstruction are labeled with ${ }^{\text {a }}$

having an average quality of 20 over a $30 \mathrm{bps}$ sliding window based on the phred algorithm were truncated, and trimmed reads having less than $75 \%$ of their original length, as well as their paired reads, were removed; 2) Removal of reads contaminated by adapters; 3 ) Removal of reads with ambiguous bases ( $\mathrm{N}$ bases), and their paired reads; 4) Removal of reads with low complexity. Paired-end reads were generated using the Illumina MiSeq platform, and the reads with sequencing adapters, $\mathrm{N}$ bases, poly-bases, and low quality bases were filtered out using default parameters. If two paired-end reads overlapped with 1) a minimum overlap of $15 \mathrm{bp}$ and 2) a mismatching ratio in the overlapped region $<=0.1$, the consensus sequence was generated by FLASH v1.2.11 (Magoč and Salzberg 2011). Paired-end reads without overlaps were removed.

\section{Construction of molecular phylogenetic trees and recognition of phylogenetic species}

Before multilocus molecular analysis, we distinguished the lineages of Pleurotus, which probably represent reproductively isolated species. To do this, nucleotide sequences of the internal transcribed spacer (ITS) region and the gene for RNA polymerase II second largest subunit (RPB2) newly generated and from GenBank were listed in Table 1 and Additional file 2. ITS and RPB2 sequences were aligned using the multiple sequence alignment algorithm FFT-NS-2 implemented in MAFFT v.7.245 (Katoh et al. 2002), respectively. The resulting alignment of ITS and RPB2 were subjected to molecular phylogenetic inference based on the maximum likelihood (ML) method using RAxML v.8.1.5 (Stamatakis 2006). The selected substitution models for the four partitions were as follows: GTR + G for ITS, SYM + I + G for $R P B 2$. Bootstrap support values were calculated from 1000 standard bootstrap replications, as implemented in RAxML. According to recognition terminal clades of
ITS phylogenetic tree, $R P B 2$ sequence variations among specimens within each of several known species were compared and a cutoff value was then proposed to define species limits. Specifically, in our study, five species, Pleurotus abieticola R.H. Petersen \& K.W. Hughes, P. citrinopileatus Singer, $P$. eryngii var. ferulae (Lanzi) Sacc., P. eryngii (DC.) Quél., and P. placentodes, were used to identify the range of intra-specific variation and establish a conservative cutoff value for phylogenetic species identification, with the highest intraspecific variation of these five species chosen as our cutoff value. These species were selected here because they have been well studied both morphologically and phylogenetically by other researchers (Li et al. 2017; Zhao et al. 2016b) or by our research group (unpublished data). Based on the phylogenetic tree generated from the $R P B 2$ data, each terminal branch with a high statistical support was treated provisionally as one species. Subsequently, intraand inter-specific variations of these provisionally adopted species were then calculated in MEGA 5 (Tamura et al. 2011). Any provisionally adopted species was accepted as a valid species if it showed greater divergence from its closest sister taxa than the cutoff value. In contrast, the taxa with divergence lower than the cutoff value were considered as belonging to the same species.

The tags obtained from the next-generation sequencing from each gene were separately aligned with nucleotide sequences of the same gene from Strobilomyces aff. confusus (GenBank accession numbers: LC082671LC084587) using MAFFT v.7.245 (Katoh et al. 2002), by which non-orthologous sequences (sequences obtained from non-specific amplification) were removed. Exonintron boundaries were also identified with the aligned orthologous sequences. The aligned sequences of introns were separately cleaned using GBLOCKS v.0.91b (Castresana 2000), with options 'Allow smaller final blocks' 
and 'Allow gap positions within the final blocks'. The nuclear single-copy orthologous genes whose sequences were not detected in more than half of the total samples were removed to minimize potential biases caused by missing data or alignment gaps. The remaining $40 \mathrm{nu}-$ clear single-copy orthologous genes were subjected to subsequent analyses.

Phylogenetic inference based on the ML method was performed using RAxML as mentioned. The optimal substitution model was determined with the Akaike Information Criterion as implemented in PAUP* 4.0b10 (Swofford 2003) and MrModeltest v2.3 (Nylander 2004) (Additional file 3). Phylogenetic analysis was also performed with Bayesian inference using MRBAYES v.3.2.1 (Ronquist et al. 2012). BI analysis consisting of four simultaneous Markov chain Monte Carlo (MCMC) chains was run over 20 million generations with trees sampled every 100 generations. The sampling of the posterior distribution was considered to be adequate when the average standard deviation of split frequencies was lower than 0.01 . Chain convergence was determined by checking the effective sampling size (ESS $>200$ ) in Tracer 1.7 (Rambaut et al. 2018). By omitting the first $25 \%$ of trees as burn-ins using the "sump" and "sumt" commands, a majority rule consensus tree was generated.

Molecular phylogenetic species of the $P$. ostreatus species complex were delimited according to the genealogical concordance phylogenetic species recognition (GCPSR) and genealogical non-discordance criteria (Dettman et al. 2003, 2006). In brief, two GCPSR-based criteria must be fulfilled when a phylogenetic species is defined: (1) the clade is well supported in the majority $(3 / 4)$ of the single-locus genealogies; (2) the clade is well supported by at least one single-locus genealogy, and is not contradicted in any other single-locus genealogy at the same level of support. Such clades were assessed using both ML bootstrap (MLB $\geq 70 \%$ ) and Bayesian posterior probabilities $(\mathrm{BPP} \geq 0.95)$. Each phylogenetic species had to be distinct and well differentiated from the other species, and all individuals had to be placed within the same phylogenetic species. For any clade which failed to obtain multi-gene sequences from at least two samples, it was also accepted as a potential independent phylogenetic lineage if it showed long branches as sequence variation from its sister groups and it possessed stable morphological difference.

Finally, five data matrices were compiled for different analyses. Dataset I (ITS) was used to identify most species of Pleurotus and Hohenbuehelia on the basis of molecular evidence and the previous phylogenetic research (Li et al. 2017; Zhao et al. 2016b). Dataset II (RPB2) was used to detect potential phylogenetic species. Dataset III (40 nuclear single-copy orthologous gene matrices and concatenated tree) was used to test the monophyly of the $P$. ostreatus species complex and for phylogenetic species recognition. Using TBLASTN from the DOE Joint Genome Institute (JGI, http://jgi.doe.gov/fungi), nucleotide sequences homologous to these single-copy genes were sought in whole genome shotgun sequencing datasets from 30 species in the Agaricales, Boletales, Polyporales, Russulales and other orders (Additional file 4). Dataset IV (40 single-copy orthologous genes) included an extensive sampling of non-Pleurotus outgroups from the JGI, and was used to estimate divergence time of the $P$. ostreatus species complex. Dataset $\mathrm{V}$ (40 single-copy orthologous genes) was subset of Dataset III, but was mostly reduced to one or two terminal per phylogenetic species from different geographical areas. It was used for diversification analyses and ancestral state reconstruction.

\section{Calibration procedure}

A secondary calibration procedure from Renner (2005) has been used for fungi in several studies (Cai et al. 2014; Feng et al. 2012; Han et al. 2018; Wilson et al. 2012) and was employed in this study to estimate node ages. Dated phylogenies for both Datasets IV and V were reconstructed in BEAST v1.8.1 (Drummond et al. 2012). For Dataset IV, we used the calibration: the divergence between Ascomycota and Basidiomycota inferred from the fossil Paleopyrenomycites devonicus Taylor, Hass, Kerp, M. Krings \& Hanlin. For the calibration, a normal distribution was applied by setting the mean and the standard deviation to 582.5 and 50.15 , respectively (Berbee and Taylor 2010; Lücking et al. 2009). All introns within 40 nuclear single-copy orthologous genes were removed from Dataset IV because of the difficulty in alignment when large numbers of less closely related taxa are present. We selected the best partition schemes and evolutionary models for Dataset IV using MrModeltest v.3.2.1 (Ronquist et al. 2012) (Additional file 3). BEAUti v1.8.1 settings employed a Bayesian uncorrelated lognormal relaxed molecular clock and a Yule prior. Two independent MCMC runs were conducted for 100 million generations, sampling every 5000 generations. Log files of the two runs were combined using LogCombiner by setting the $25 \%$ logs as burn-ins and then analyzed in Tracer 1.7 (Rambaut et al. 2018) to confirm that the analysis reached a stationary distribution. The resulting trees were also interpreted in TreeAnnotator v1.8.1 to achieve a maximum clade credibility (MCC) tree. The estimated crown age of the $P$. ostreatus species complex by Dataset IV was used as the calibration point to date Dataset $\mathrm{V}$ by setting the prior to a normal distribution. The selection of evolutionary models of Dataset V, and the other protocols, followed the methods given for Dataset IV. 


\section{Diversification analysis}

We employed several packages in R 3.1.3 ( $\mathrm{R}$ Development Core Team 2014) to explore changes in the diversification rate within the $P$. ostreatus species complex over time (Additional file 5). First, a maximum likelihood method implemented in the package "Laser" (Rabosky 2006) was used to determine if the diversification rate changed over time. Two rate-constant models (pure birth and birth-death) and three rate-variable diversification models (a logistic density-dependent, an exponential density-dependent and a yule2rate model) were fitted to the MCC tree (Akaike 1981). Second, we visually assessed the timing and tempo of diversification by constructing lineages through time (LTT) plots using "Ape" (Paradis et al. 2004). Third, we applied Bayesian analysis of macroevolutionary mixtures (BAMM 2.5.0) and "Bammtools" (Rabosky et al. 2014) to detect the location of diversification rate shift within the P. ostreatus species complex. Five species or varieties $(P$. columbinus Quél., P. eous (Berk.) Sacc., P. subareolatus Peck, $P$. eryngii var. thapsiae Venturella et al., $P$. eryngii var. tingitanus Lewinsohn) according to our phylogenetic tree of ITS and previous studies (Zervakis et al. 2014, 2019; Zervakis and Balis 1996) were not included in diversification analyses, so a command about "useGlobalSamplingProbability $=1$; globalSamplingFraction $=0.80$ " was setting in controlfile to generate unbiased estimates of speciation and extinction.

\section{Reconstruction of ancestral state}

Seven areas were delimited based on the tectonic history of continents and the distribution data of Pleurotus: $\mathrm{A}=$ East Asia; $\mathrm{B}=$ West Asia; $\mathrm{C}=$ North America; $\mathrm{D}=$ Europe; $\mathrm{E}=$ South America; $\mathrm{F}=$ Africa. Each sample was coded on the basis of its collection locality according to the field notes and references. Based on the MCC tree from BEAST analysis of Dataset V, RASP 3.2 (Yu et al. 2015) was used to reconstruct ancestral areas through Bayesian binary MCMC (BBM) analysis and dispersalextinction-cladogenesis (DEC) analysis. MCMC chains in the BBM were run for 10 million generations with a sampling frequency of 100, excluding the first 1000 generations as burn-in.

\section{RESULTS}

\section{Phylogenetic analysis}

Of the 50 nuclear single-copy orthologous genes, forty were shared between at least 30 samples and were therefore used for reconstructing phylogenies. Thus, we got 40 single-copy nuclear sequence matrices rather than 50 for phylogenetic analysis. After removal of all sequences of poor quality, 1759 single-copy nucleotide sequences of 51 Pleurotus species and outgroup species were newly sequenced in this study; these sequences were deposited in GenBank (GenBank accession numbers: MN546051MN546733, MN557857-MN558583, MN565733MN565779, MN919217-MN919343, MN974593MN974674, MT157415-MT157507). None of the ML trees from the individual gene analyses revealed any major conflicts among the datasets. Each nuclear singlecopy orthologous gene analyzed separately resulted in fairly unresolved topologies, but they were all consistent with one another (Additional file 6). The concatenated dataset, after exclusion of the ambiguously aligned regions, had an alignment length of 12,995 bp. When all of nuclear single-copy orthologous genes were concatenated, they resulted in a single, completely resolved phylogeny.

The phylogenetic analyses with a concatenated fortygene dataset strongly supported the monophyly of the $P$. ostreatus species complex (100\% MLB and 1.0 BPP value; Fig. 1). Within the P. ostreatus species complex, three distinct clades (Clades I, II and III) can be discerned, all of which are well-supported under both the maximum likelihood and Bayesian analyses. Some of these clades were further segregated into smaller groups with strong support (Fig. 1). Clade I was the basal most lineages in the P. ostreatus species complex and was sister to the Clades II and III collectively. Clade II was sister to Clade III, and consisted of three subclades of samples of North American, East Asian, European and African origin, respectively. The three subclades, named here Clades IIa, IIb, and IIc, could be inferred. Although characterized by short internal branches, the phylogenetic relationships within Clade IIc were resolved into four distinct lineages from East Asia, Europe, North America and Africa, respectively with $100 \%$ bootstrap support. Clade III was the largest of the three clades, and had four subclades (Clades IIIa, IIIb, IIIc, and IIId) with high statistical support. Clade IIIa, at the base of Clade III, formed a unique clade consisted of a single collection from South America, and its phylogenetic relationship to the taxa occurring in the Northern Hemisphere was highly supported (99\% MLB; 0.97 BPP). Clades IIIb and IIIc were well supported as sisters to Clade IIId (100\% MLB; 1.0 BPP). Clade IIIb (100\% MLB; 1.0 BPP) included two lineages from North America and East Asia, respectively. In Clade IIIc, the collection from southwestern China clustered with Japanese accession with high support (100\% MLB; $1.0 \mathrm{BPP})$, and were together a sister group to the north Chinese collections and European collections. Phylogenetic analyses also identified a relatively recent and rapid species-rich radiation within Clade IIId, which comprised close to two thirds of the phylogenetic species in Clade III. Furthermore, Clade IIId was a monophyletic group, and phylogenetic analysis placed $P$. tuoliensis as the most basal species of the subclade. Additionally, $P$. eryngii var. 


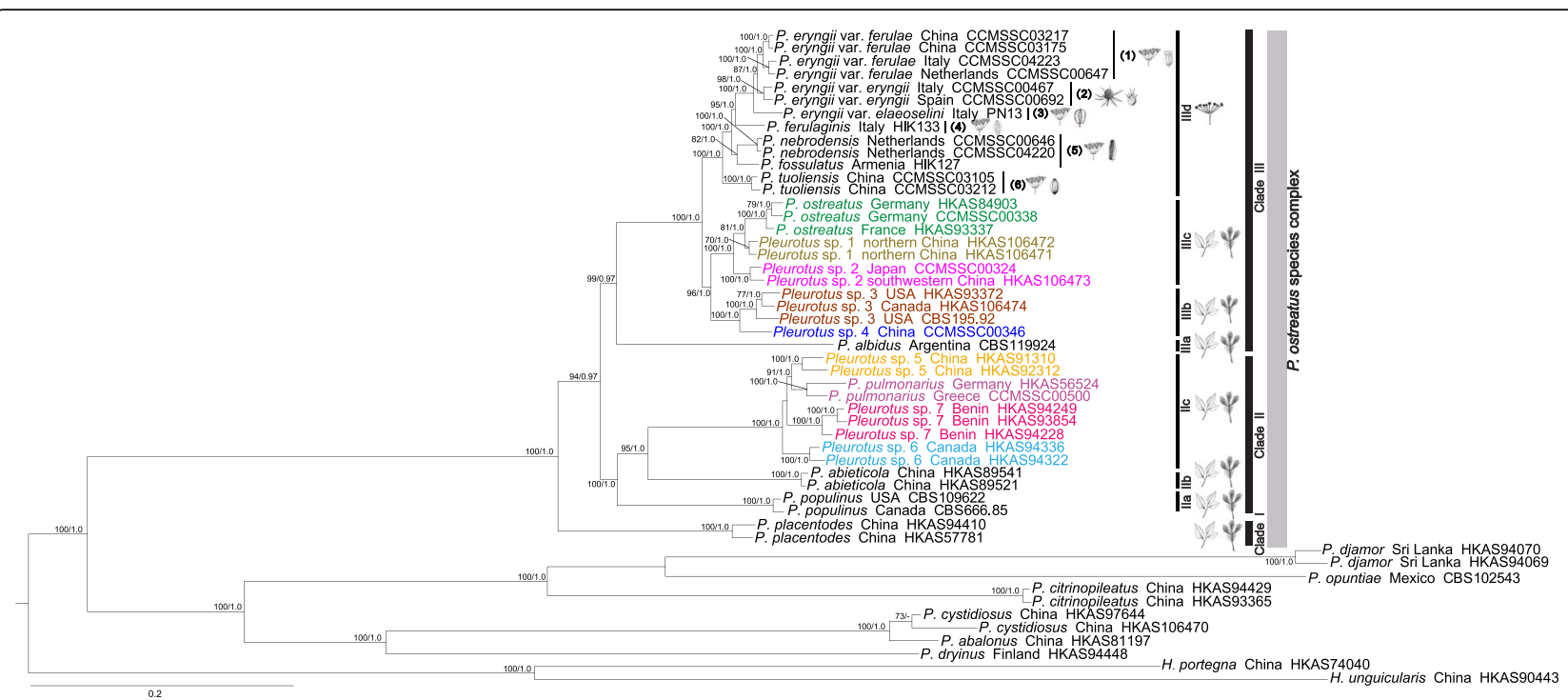

Fig. 1 Phylogenetic tree generated from a forty-locus dataset. The branch support values are indicated by the numbers above the branches ( $M L B \geq 70 \%, B P P \geq 0.95$ ). The $P$. ostreatus species complex is marked on the right of the phylogenetic tree, three major clades and seven subclades are in the black frames. Every phylogenetic species in Clades IIc, IIIb and IIlc is marked with different colors. The line-drawings of substrate plants and seeds are from Flora of China and Google. Table 1 includes the details of reference collections for all species

ferulae from Europe was clustered with a counterpart from northwestern China with of 100\% MLB support.

\section{Phylogenetic species recognition}

The maximum likelihood analysis was conducted using ITS sequences from 120 taxa, with Hohenbuehelia designated as outgroup. Sequences of ITS rDNA showed limited variation among the species within the $P$. ostreatus species complex. Most phylogenetic relationships among species of the complex were not well resolved (Additional file 7). The phylogenetic relationships of the Clades IIIb and IIIc remained uncertain. Within Clade IIIc, several samples were clustered with three specimens named 'P. spodoleucus (Fr.) Quél.' and 'P. columbinus', respectively, while the others were nested with the Clade IIIb and two specimens named 'P. eous'. Similarly, the phylogenetic relationships between $P$. eryngii and its varieties were not clear. Some good ML bootstrapping support in the terminal clades in this dataset generally allowed us to partly delineate species boundaries. The preliminary phylogenetic analyses of ITS rDNA sequences and from the $P$. ostreatus species complex reference taxa distinguished 12 major clades.

As shown in Additional file 8, of the five species chosen as references for identifying the range of intraspecific variation of $R P B 2$ sequences, $P$. abieticola showed the highest value $(0.93 \%)$, while the lowest (0) was observed in P. tuoliensis (C.J. Mou) M.R. Zhao \& J.X. Zhang. Thus, $0.93 \%$ was chose as the cutoff value for the phylogenetic species identification using $R P B 2$ sequences. Taking this value as a threshold, Pleurotus sp. 3 and Pleurotus sp. 4 with a high inter-specific variation $(1.74 \%)$ would be regard as independent species, respectively. Meanwhile, our provisionally adopted "pulmonarius-clade" and "ostreatus-clade" showed intraspecific divergence much higher than $0.93 \%(1.81 \%$ and $1.08 \%$, respectively). Both the two temporarily accepted species consisted of more than one species based on the intra-specific variations and phylogenetic tree (Additional file 9), and therefore may represent more separate species, respectively. Other provisionally adopted species showed relatively high interspecific and low intraspecific variations and thus they were most likely valid phylogenetic species.

Among all twenty of the recognized phylogenetic species of the $P$. ostreatus species complex, fifteen of them fulfilled the GCPSR criterion. Among the fifteen phylogenetic species, three (P. abieticola, P. placentodes and $P$. populinus O. Hilber \& O.K. Mill.) were strongly supported by more than thirty genealogies, four (P. nebrodensis (Inzenga) Quél., P. tuoliensis, Pleurotus sp. 6 and Pleurotus sp. 7) were strongly supported as monophyletic by MLB $(\geq 70 \%)$ and BPP $(\geq 0.95)$ in more than twenty individual gene trees, two (P. ostreatus and Pleurotus $\mathrm{sp} .3$ ) were resolved as monophyletic in more than ten individual gene trees, and the other six of them, namely $P$. eryngii var. eryngii, $P$. eryngii var. ferulae, $P$. pulmonarius (Fr.) Quél., Pleurotus sp. 1, Pleurotus sp. 2 and Pleurotus sp. 5, only formed monophyletic groups in less than ten gene trees (Additional files 6, and 10). Gsh1 gene had the highest resolution and ten phylogenetic species ( $P$. abieticola, $P$. eryngii var. eryngii, $P$. 
eryngii var. ferulae, $P$. nebrodensis, $P$. placentode, $P$. pulmonarius, P. tuoliensis, Pleurotus sp. 1, Pleurotus sp. 2 and Pleurotus sp. 5) formed monophyletic groups in the gene tree. Although one putative species lineage ( $P$. albidus (Berk.) Pegler, P. eryngii var. elaeoselini Venturella et al., $P$. ferulaginis Venturella et al., $P$. fossulatus (Cooke) Sacc., Pleurotus sp. 4) was represented by single collection and therefore the monophyly could not be tested, they were considered to be phylogenetically distinct because they were genetically divergent from their sisters and could be clearly recognized by other means. We recognized a total of 20 phylogenetic species based on the criteria listed above (Fig. 1; Additional files 6, and 10): seven were revealed here for the first time, and 13 could be assigned to formally described species. Taxonomic treatment of the $P$. ostreatus species complex with seven species ( $P$. abieticola, $P$. cf. floridanus, $P$. eryngii, $P$. ostreatus, $P$. placentodes, $P$. pulmonarius and P. tuoliensis) according to $\mathrm{Li}$ et al. (2017) was included with our results, which were strongly supported. Clade I comprised only $P$. placentodes, known from the subalpine habitat of the eastern Himalayan and Hengduan Mountains region, southwestern China (Liu et al. 2016). Pleurotus abieticola, P. populinus, P. pulmonarius, Pleurotus sp. 5, Pleurotus sp. 6 and Pleurotus sp. 7 were clustered together in Clade II. Pleurotus albidus, $P$. ostreatus, Pleurotus sp. 1, Pleurotus sp. 2, Pleurotus sp. 3 and Pleurotus sp. 4 were clustered with $P$. eryngii var. elaeoselini, $P$. eryngii var. eryngii, $P$. eryngii var. ferulae, $P$. ferulaginis, $P$. fossulatus, $P$. nebrodensis, and P. tuoliensis in Clade III. The phylogenetic tree also showed that $P$. tuoliensis, and $P$. nebrodensis were distinct species respectively, rather than varieties of $P$. eryngii.

\section{Bayesian estimation of divergence times of $P$. ostreatus species complex}

The mean ages, 95\% HPD intervals and Bayesian Posterior Probability values of all labelled nodes within Pleurotus are indicated in the chronogram (Fig. 2) and in Table 2. Topologies obtained for the Bayesian consensus tree (Fig. 1) and BEAST analysis (Fig. 2) based on the forty-gene dataset were almost identical. Our Bayesian dating, based on Dataset IV, suggested that the stem age of Pleurotus was estimated to be $153 \mathrm{Ma}$ (135-171 Ma, 95\% HPD; node 25) during the late Jurassic. The data suggest an ancient divergence of the major lineage $P$. ostreatus species complex from allied taxa during the late Jurassic, with the diversification of lineages within the complex having occurred mainly during the late Eocene (39 Ma, 33-44 Ma, 95\% HPD; node 26). The earliest divergence formed Clade I, comprising collections from the eastern Himalayan and Hengduan Mountains region (HHM) (Fig. 2; Table 2). Clades II and III diverged at about $32 \mathrm{Ma}$ (27-35 Ma, 95\% HPD; node 27). The crown ages of Clades II and III were estimated at about $28 \mathrm{Ma}(24-32 \mathrm{Ma}, 95 \%$ HPD; node 28) and $29 \mathrm{Ma}$ (24-32 Ma, 95\% HPD; node $29)$, respectively.

\section{Diversification of the $P$. ostreatus species complex}

Our Laser results supported a pure birth model of diversification, with the diversification rate-constancy statistic

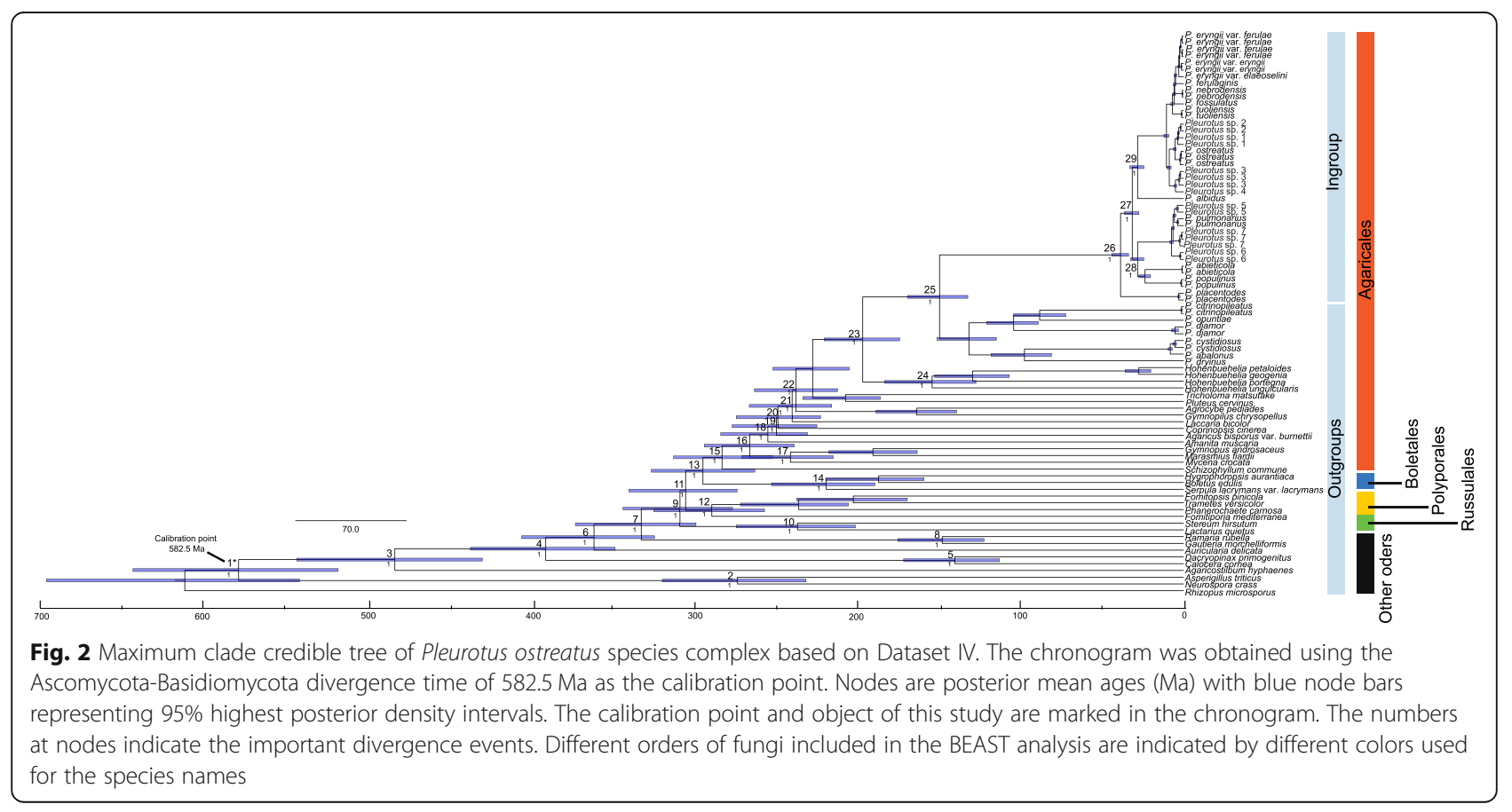


Table 2 Estimated node ages and 95\% HPD (Ma)

\begin{tabular}{|c|c|c|c|c|}
\hline Clade lable for crown nodes & Node & $\begin{array}{l}\text { Median age } \\
\text { (Ma) }\end{array}$ & $\begin{array}{l}95 \% \mathrm{HPD} \\
(\mathrm{Ma})\end{array}$ & Posterior Probability \\
\hline Ascomcota/Basidiomycota & 1 & 591 & $529-653$ & 1 \\
\hline Ascomcota & 2 & 280 & $237-325$ & 1 \\
\hline Pucciniomycotina/Basidiomycota & 3 & 492 & $437-546$ & 1 \\
\hline Dacrymycetes/Agaricomycetes & 4 & 398 & $357-442$ & 1 \\
\hline Dacrymycetes & 5 & 143 & $117-169$ & 1 \\
\hline Auriculariales/Agaricomycetes & 6 & 368 & $330-408$ & 1 \\
\hline Gomphales-Hysterangiales/Agaricomycetes & 7 & 340 & $305-376$ & 1 \\
\hline Gomphales-Hysterangiales & 8 & 152 & $128-178$ & 1 \\
\hline Russulales-Hymenochaetales-Polyporales/Agaricales-Boletales & 9 & 315 & 283-349 & 1 \\
\hline Russulales & 10 & 241 & $209-275$ & 1 \\
\hline Hymenochaetales-Polyporales & 11 & 311 & $279-344$ & 1 \\
\hline Hymenochaetales & 12 & 296 & $264-329$ & 1 \\
\hline Boletales/Agaricales & 13 & 301 & $271-334$ & 1 \\
\hline Boletales & 14 & 224 & $196-253$ & 1 \\
\hline \multirow[t]{8}{*}{ Agaricales } & 15 & 289 & $259-320$ & 1 \\
\hline & 16 & 272 & $244-302$ & 1 \\
\hline & 17 & 261 & $234-290$ & 1 \\
\hline & 18 & 248 & $219-276$ & 1 \\
\hline & 19 & 256 & $230-284$ & 1 \\
\hline & 20 & 255 & $228-282$ & 1 \\
\hline & 21 & 246 & $220-273$ & 1 \\
\hline & 22 & 244 & $218-270$ & 1 \\
\hline Pleurotus/Hohenbuehelia & 23 & 201 & $179-224$ & 1 \\
\hline Hohenbuehelia & 24 & 158 & $132-185$ & 1 \\
\hline Pleurotus & 25 & 153 & $135-171$ & 1 \\
\hline \multirow[t]{4}{*}{ Pleurotus ostreatus complex } & 26 & 39 & $33-44$ & 1 \\
\hline & 27 & 32 & $27-35$ & 1 \\
\hline & 28 & 28 & $24-32$ & 1 \\
\hline & 29 & 29 & $24-32$ & 1 \\
\hline
\end{tabular}

$\triangle \mathrm{AIC}_{\mathrm{RC}}$ being -0.69 . Furthermore, the LTT plot suggested that lineages within the $P$. ostreatus species complex mainly accumulated during the late Eocene and the late Miocene, the diversification rate within the P. ostreatus species complex increased significantly in the late Miocene especially (Fig. 3f). One of the two tested prior (2) from the BAMM analyses identified only one rate shift at the stem of subclades IIIb, IIIc and IIId; however, the remaining prior (1) consistently showed no node as having potential shift (Fig. 3c). In the maximum a posteriori configuration, a rate shift at the stem of subclades IIIb, IIIc and IIId had a marginal shift probability (Fig. 3c). The rate-through-time plots suggested that the global speciation rate of the $P$. ostreatus species complex significantly accelerated from the late Miocene towards the present
(Fig. 3e). The increases identified from the speciation ratethrough-time curve were concordant with the positions of rate shifts along the phylogeny (e.g. stem of subclades IIIb, IIIc and IIId; Fig. 3c, e). In addition, the macroevolutionary cohort analysis for diversification revealed a certain level of heterogeneity in the diversification regimes within the $P$. ostreatus species complex (Fig. 3d).

\section{Ancestral area reconstruction of the $P$. ostreatus species complex}

The $P$. ostreatus species complex was inferred to have a mean crown age of $39.05 \mathrm{Ma}$ (33.84-44.11 Ma, 95\% HPD) by Dataset IV, and this value was used as a calibration point for estimating the ages of major clades by setting the prior to a normal distribution, with the mean 
(c)
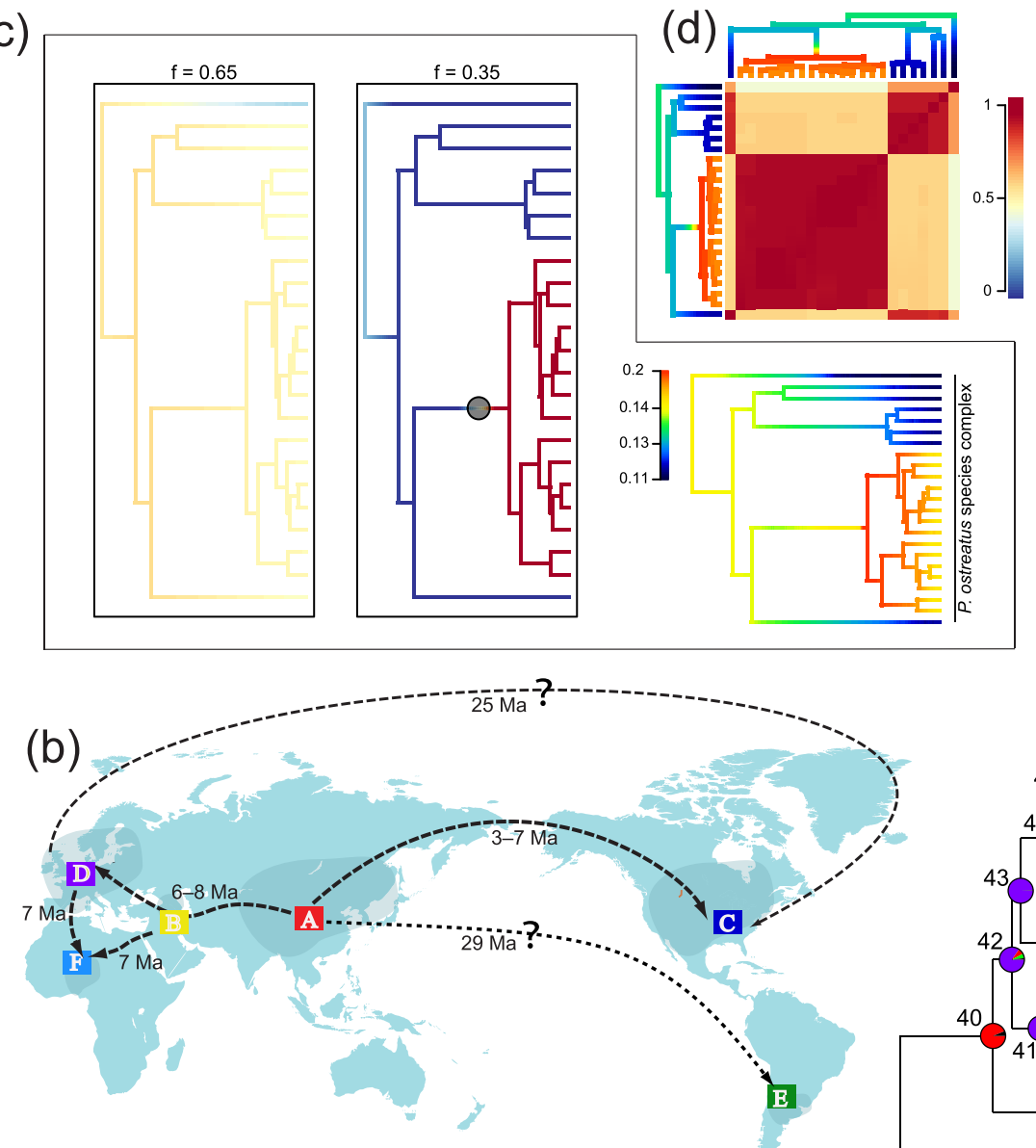

40 (f)

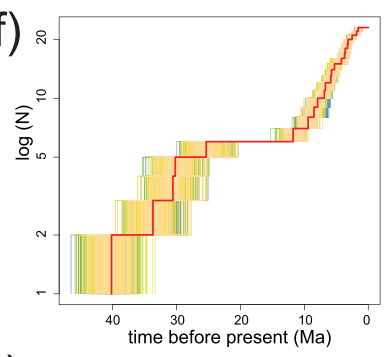

(e)

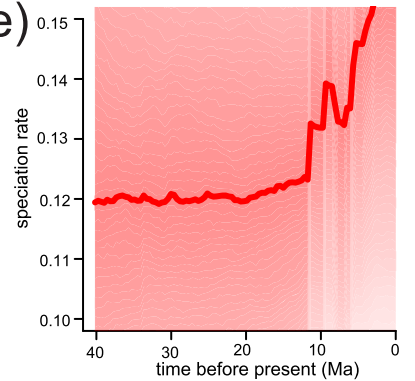

P. eryngii var. ferulae

P. eryngii var. ferulae

44 $P$. eryngii var. eryngii

P. eryngii var. elaeoselini

P. ferulaginis

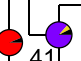

P. nebrodensis

P. fossulatus

P. tuoliensis
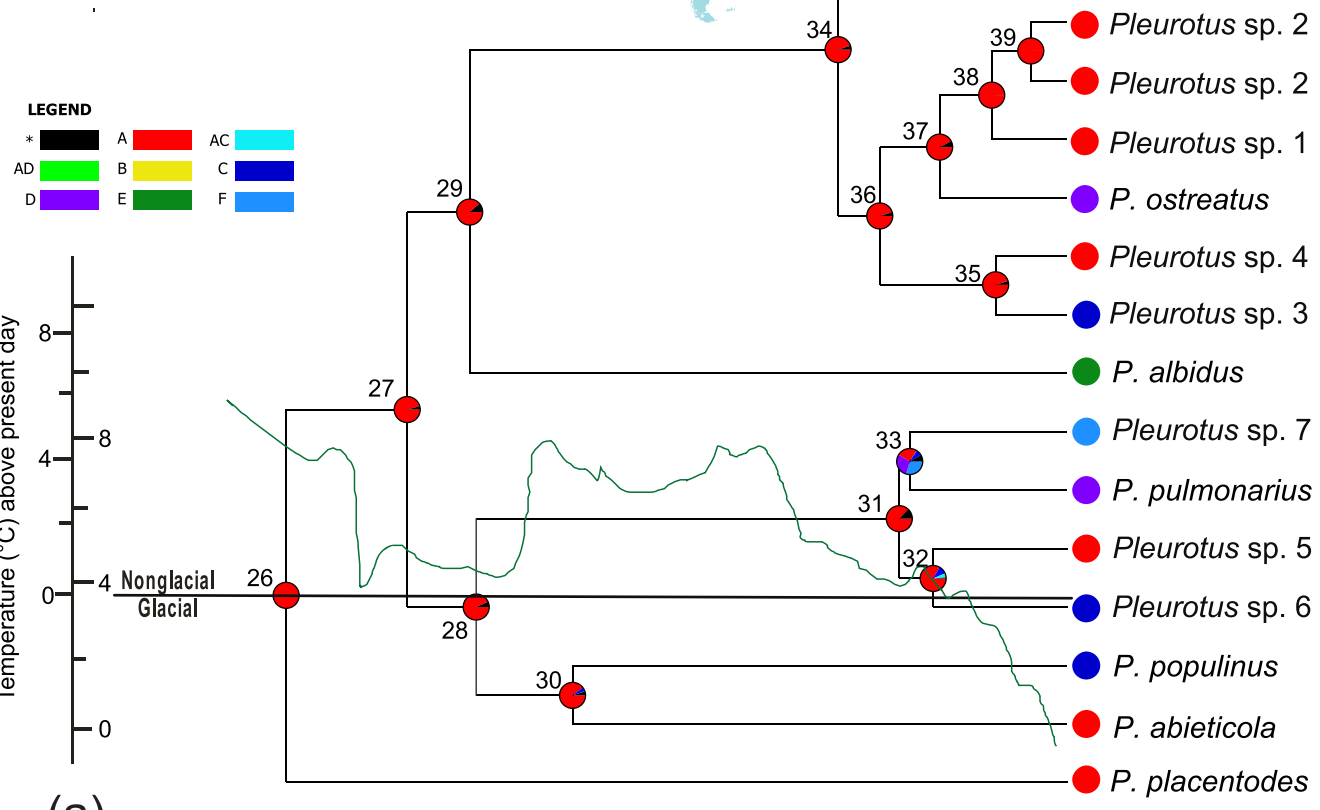

(a)

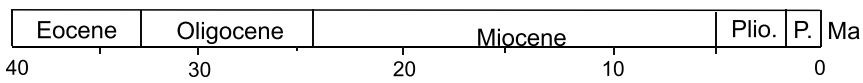

Fig. 3 (See legend on next page.) 
(See figure on previous page.)

Fig. 3 Chronogram of Pleurotus ostreatus species complex. The time-scale is set to the mean divergence dates produced in BEAST. Numbered nodes refer to mean divergence dates and their 95\% HPD provide in Table 3. Small colored boxes indicate coded character states. a Ancestral area reconstruction with pie charts colored according to area. The green curve represents global temperature change in the geological history according to Zachos et al. (2001). b The area division and inferred dispersal route of $P$. ostreatus species complex. c A phylotate plot for distinct net diversification rates by mapping colors to rates on all branches, and $95 \%$ credible set of macroevolutionary shift configurations identified based on branch-specific marginal odds ratios. $\mathbf{d}$ Macroevolutionary cohort analysis with pairwise probabilities. e Plots of net diversification rates through time for lineages with 95\% credible interval. $\mathbf{f} L T$ T plots from 95\% HPD trees and a consensus tree annotated from the BEAST analysis

and standard deviation set to 39.05 and 2.62 , respectively, which covers the 95\% HPD of the crown age. The optimized ancestral areas inferred for internal nodes of Dataset V are mostly similar in the BBM and DEC analyses and supported East Asia as the center of origin for the $P$. ostreatus species complex: estimated ancestral distributions for root nodes of the complex and its major clades were all restricted to East Asia (Fig. 3a, Table 3). The East Asia clade (Clade I) became isolated from the ancestral $P$. ostreatus species complex lineage evolving in the remaining regions. Clades II and III were estimated to have the same ancestral area (East Asia), which therefore implies that several dispersal events to North America, Europe, and Africa occurred during the late Oligocene and late Miocene (nodes 30-33 for Clade II) and to South America, North America and Europe during the middle Oligocene and late Miocene to Pliocene (nodes 29, 35, 37, 40-41 and 46 in Clade III).

\section{DISCUSSION}

\section{Phylogenetic reconstruction and rich diversity of the $P$. ostreatus species complex}

The phylogenetic relationships of the $P$. ostreatus species complex were historically largely controversial, and were based only on phylogenetic comparisons of morphological characteristics and limited gene loci, such as the ITS, IGS, LSU, TEF1 $\alpha, R P B 1$, and RPB2 sequences (Avin et al. 2014; Estrada et al. 2010; Gao et al. 2008b; He et al. 2016; Li et al. 2017; Thorn et al. 2000; Zheng et al. 2006). The availability of whole-genome single-copy orthologous genes sequencing in the $P$. ostreatus species complex enables construction of a consensus phylogenetic gene tree, which offered an unprecedented opportunity to resolve this issue. Our results provide a solid basis for inferring the relationships among the taxa within the complex (Fig. 1). First, in our phylogenetic analysis, Clade IIIb was sister to Clade IIIc with high support (96\% MLB; 1.0 BPP) (Fig. 1). Although the ML phylogenetic tree of the ITS dataset showed Clade IIIb clustered with $P$. eous (Additional file 7), the relationship was not strongly supported and $P$. eous has distinctive morphology (pileus color) and distribution (Pegler 1977). Second, we identified a single subclade marked as P. albidus (CBS119924) in Clade III, which occurs from Central America to Central Argentina on dead wood including Salix and Ulmus (Albertó et al. 2002). Third, $P$. tuoliensis was basal in Clade IIId, showing a close relationship with P. nebrodensis and P. fossulatus (Fig. 1). Pleurotus eryngii and its varieties, as well as $P$. ferulaginis formed a monophyletic group with high support $(95 \%$ MLB; 1.0 BPP), which was consistent with Zhao et al. (2016b). In addition, although the northwestern Chinese population and the Mediterranean population of $P$. eryngii var. ferulae belong to the same genetic group according to phylogenetic analysis, they were highly differentiated based on genetic structure and pileus color (Lewinsohn et al. 2001; Urbanelli et al. 2003; Zhao et al. 2016a, 2016b). Our results also showed a more comprehensive molecular phylogenetic frame of Pleurotus, which was divided into three major clades (Fig. 1). The three major clades might represent three subgenera or three sections, and two clades (the $P$. ostreatus species complex and "cystidiosus-clade") were consistent with Hilber (1982) (subgenera Pleurotus, Coremioplaurotus) respectively, the remaining one was unconformable.

Estimating worldwide species diversity for the $P$. ostreatus species complex has been difficult because of subtle morphological differences, and limited DNA sequence differences among different species (Gao et al. 2008a; Singer 1986; Zheng et al. 2006). Our forty-gene phylogenetic analysis of the global $P$. ostreatus species complex specimens based on high-throughput sequencing distinguished 20 phylogenetic species (Fig. 1), which is much more diverse than the previous studies (Li et al. 2017; Menolli Jr. et al. 2014; Zervakis and Labarère 1992). The number of phylogenetic species within Clade II increased from two ( $P$. abieticola, $P$. pulmonarius) to six (P. abieticola, P. populinus, P. pulmonarius, Pleurotus sp. 5, Pleurotus sp. 6, and Pleurotus sp. 7). It was previously proposed that the North American population of $P$. pulmonarius is different from the European population, in morphology, mating behavior and other characters (Petersen and Hughes 1993; Vilgalys et al. 1993), and this was confirmed by our data. We recognized four phylogenetic species within Clade IIc following to GCPSR criterion, occurring in East Asia, Europe, North America, and Africa, respectively, although they are poorly differentiated morphologically (Fig. 1; Additional file 10). Similarly, taking account of genetic differences associated with 
Table 3 Divergence time estimates of BEAST analyses for major nodes of Pleurotus ostreatus species complex

\begin{tabular}{|c|c|c|c|c|c|c|c|}
\hline \multirow[t]{2}{*}{ Node } & \multirow{2}{*}{$\begin{array}{l}\text { Mean }(95 \% \\
\text { HPD) Ma }\end{array}$} & \multicolumn{2}{|c|}{ Results of ancestral area reconstruction Area/RP } & \multirow[t]{2}{*}{ Node } & \multirow{2}{*}{$\begin{array}{l}\text { Mean }(95 \% \\
\text { HPD) Ma }\end{array}$} & \multicolumn{2}{|c|}{ Results of ancestral area reconstruction Area/RP } \\
\hline & & BBM & DEC & & & BBM & DEC \\
\hline \multirow[t]{6}{*}{26} & $39(33-44)$ & A/0.99 & $\mathrm{A} / 0.35$ & 37 & $6(4-8)$ & A/0.93 & AD/0.66 \\
\hline & & NA/0.01 & AC/0.16 & & & NA/0.07 & $\mathrm{A} / 0.34$ \\
\hline & & & $\mathrm{AD} / 0.15$ & 38 & $4(2-6)$ & A/0.99 & $A / 1.0$ \\
\hline & & & $\mathrm{AE} / 0.13$ & & & NA/0.01 & \\
\hline & & & $\mathrm{AF} / 0.11$ & 39 & $2(1-4)$ & A/0.99 & $A / 1.0$ \\
\hline & & & $\mathrm{AB} / 0.10$ & & & NA/0.01 & \\
\hline \multirow[t]{4}{*}{27} & $32(27-35)$ & A/0.97 & A/0.67 & 40 & $6(5-8)$ & A/0.95 & $A D / 1.0$ \\
\hline & & NA/0.03 & AC/0.12 & & & NA/0.05 & \\
\hline & & & AD/0.11 & 41 & $4(2-7)$ & D/0.83 & $\mathrm{BD} / 0.63$ \\
\hline & & & $\mathrm{AE} / 0.10$ & & & $\mathrm{~B} / 0.08$ & D/0.37 \\
\hline \multirow[t]{3}{*}{28} & $28(24-32)$ & $\mathrm{A} / 0.89$ & $\mathrm{~A} / 0.84$ & & & NA/0.09 & \\
\hline & & AC/0.06 & $\mathrm{AC} / 0.16$ & 42 & $5(4-6)$ & $\mathrm{D} / 0.83$ & $\mathrm{D} / 1.0$ \\
\hline & & NA/0.05 & & & & A/0.09 & \\
\hline \multirow[t]{3}{*}{29} & $29(24-32)$ & A/0.92 & $\mathrm{A} / 0.73$ & & & $\mathrm{AD} / 0.06$ & \\
\hline & & NA/0.08 & $\mathrm{AE} / 0.17$ & & & NA/0.02 & \\
\hline & & & AD/0.10 & 43 & $5(4-7)$ & D/0.99 & $\mathrm{D} / 1.0$ \\
\hline \multirow[t]{3}{*}{30} & $25(8-31)$ & A/0.96 & A/0.60 & & & NA/0.01 & \\
\hline & & NA/0.04 & AC/0.29 & 44 & $3(2-4)$ & D/0.99 & $\mathrm{D} / 0.87$ \\
\hline & & & $C / 0.11$ & & & NA/0.01 & AD/0.13 \\
\hline \multirow[t]{4}{*}{31} & $8(6-11)$ & $\mathrm{A} / 0.88$ & AD/0.33 & 45 & $2(2-4)$ & $\mathrm{D} / 0.99$ & $\mathrm{D} / 0.78$ \\
\hline & & NA/0.12 & AF/0.31 & & & NA/0.01 & AD/0.22 \\
\hline & & & AC/0.13 & 46 & $2(1-3)$ & $\mathrm{D} / 0.98$ & $\mathrm{AD} / 0.81$ \\
\hline & & & $\mathrm{CD} / 0.10$ & & & NA/0.02 & $\mathrm{D} / 0.19$ \\
\hline
\end{tabular}

NA/0.04

$32 \quad 7(5-10) \quad \mathrm{A} / 0.81 \quad \mathrm{AC} / 0.48$

$\mathrm{C} / 0.12 \quad \mathrm{~A} / 0.40$

NA/0.07 C/0.12

$33 \quad 7(5-11) \quad \mathrm{A} / 0.32 \quad \mathrm{D} / 0.32$

$D / 0.31 \quad F / 0.30$

F/0.23 DF/0.11

C/0.05 A/0.08

NA/0.09 AD/0.07

AF/0.07

$\mathrm{C} / 0.05$

$\mathrm{AD} / 0.59$

A/0.41

$\mathrm{AC} / 1.0$

A/0.67

$\mathrm{AD} / 0.22$

$\mathrm{AC} / 0.11$
Table 3 Divergence time estimates of BEAST analyses for major nodes of Pleurotus ostreatus species complex (Continued)

RP represents relative probability

geological origins, the terminal lineages of Clade IIIc were divided into three phylogenetic species $(P$. ostreatus, Pleurotus sp. 1 and Pleurotus sp. 2). Our results suggested that DNA sequences may have evolved faster than morphological characters in these phylogenetic species and these taxa might be relatively young, and have had insufficient time to accumulate morphological divergence. In Clade III, the total number of phylogenetic species increased significantly, with seven taxa belonging to Clade IIId. Of these, four are sympatric ( $P$. eryngii var. elaeoselini, $P$. eryngii var. eryngii, $P$. ferulaginis, and $P$. nebrodensis), and are mostly restricted to Mediterranean Europe from sea level to $2000 \mathrm{~m}$, one species is common to West and Central Asia ( $P$. fossulatus), one to northwestern China and West Asia ( $P$. tuoliensis), one to Mediterranean Europe and northwestern China (P. eryngii var. ferulae) (Fig. 1).

Dating of the origin of the $P$. ostreatus species complex To our knowledge, the dating analyses in our study have provided the first deep insight into the temporal and 
spatial evolution of the $P$. ostreatus species complex. Our data suggest that divergence of the genus Pleurotus probably occurred in the late Jurassic (153 Ma, node 25; Fig. 2; Table 2) as ancient as the previously suggested $200 \mathrm{Ma}$ (Vilgalys and Sun 1994b). Considering the fossil record documented the existence of Pinaceae by the early Jurassic and Betulaceae, Fagaceae, and Salicaceae by the middle Cretaceous (Lin et al. 2010; Magallón et al. 2015), this estimation seems reasonable. However, the most recent common ancestor of the $P$. ostreatus species complex was inferred to have originated in East Asia during the late Eocene (39 Ma, node 26; Fig. 2; Table 2), with the most basal modern species, P. placentodes, known from the subalpine habitat of the Himalayan Mountains. The divergences likely arose from the uplifts of the Qinghai-Tibet Plateau (QTP) and climate changes. The orogenic uplifts of the QTP are likely to have contributed strong vicariance forces that shaped the diversification process after the tectonic collision of India plate with Eurasia $50 \mathrm{Ma}$ (Yang et al. 2009). The subsequent pulse of rapid uplift of the QTP occurred between 25 and $30 \mathrm{Ma}$ (Wang et al. 2012), and this generally coincides with our date for the major diversification in the P. ostreatus species complex (32 Ma, node 27; Fig. 2; Table 2). The unique geological history of the QTP is thought to have generated heterogeneity in the soils, climate, and elevation across the region (Yang 2005). These changes arising from the uplift of the QTP might be potential drivers of evolutionary radiations in the P. ostreatus species complex, as has been suggested for many other organisms (Ran et al. 2006). On the other hand, based on our estimated timing for the earliest divergence of the P. ostreatus species complex (39 Ma, node 26; Fig. 2 ; Table 2), the period coincided closely with the second Eocene cooling between 42 and $38 \mathrm{Ma}$ (Wolfe 1978, 1997; Zachos et al. 2001). The significant global cooling during the Eocene-Oligocene transition ( $35 \mathrm{Ma}$; Zachos et al. 2001) resulted in some species adapting cold temperatures and forced others to migrate towards lower altitudes. Stochastic changes in temperature may have led to the expansion and contraction of species to small regions (refugia) in East Asia, especially in southwestern China (Harrison et al. 1992; Qiu et al. 2011).

\section{Historical diversification and migration of the $P$. ostreatus species complex}

Our data indicated that, like EMF and other SPF (Han et al. 2018; Hibbett 2001; Qin et al. 2018; Sato et al. 2017), there are distinct biogeographical patterns in the distribution of the species complex. Biogeographic analyses in our study suggested that intensification of aridity caused by rapid uplift of the QTP and retreat of the Tethys Sea in the late Miocene, climate cooling events in Quaternary glacial cycling, and substrate transitions might contribute jointly to rapid diversification of the species complex since $10 \mathrm{Ma}$ (Fig. 3a, c, e, f).

The East Asian - North American floristic disjunction pattern has been well documented in many angiosperm taxa (Tiffney 1985a; Wen 1999; Wen and Ickert-Bond 2009; Yi et al. 2015). Recently, the dispersal-vicariance theory was used to explain the biogeographic pattern of mushrooms (Cai et al. 2014; Geml et al. 2006, 2008; Hibbett 2001). Two land bridges potentially served as routes for organism exchanges between Eurasia and North America: the Bering Land Bridge (BLB, Beringia) and the North Atlantic Land Bridge (NALB) (Graham 1999; Grímsson and Denk 2005; Poore 2008; Thiede and Eldholm 1983; Tiffney 1985a, 1985b; Tiffney and Manchester 2001; Wen and Ickert-Bond 2009). There are three asynchronous East Asian - North American disjunctions inferred in the $P$. ostreatus species complex, one early (25 Ma, node 30; Fig. 3a, b; Table 3) and the other two more recently: the $P$. pulmonarius siblings $(7 \mathrm{Ma}$, node 32; Fig. 3a, b; Table 3) and species in Clade IIIb (3 Ma, node 35; Fig. 3 a, b; Table 3), respectively. All three divergence dates were more recent than the last appearance of the North Atlantic Land Bridge, which was terminated in the Eocene (40 Ma) (Graham 1999; Lickey et al. 2002). However, the North Atlantic Land Bridge cannot be excluded for the earlier migration (25 Ma, node 30; Fig. 3a, b; Table 3), as there was a possibility of a persisting bridge or closely spaced island chain through the middle Miocene (Tiffney and Manchester 2001). Similar to the previous studies, we conclude that the earlier dispersal (25 Ma) between East Asia and North America via the Beringia (Cai et al. 2014; Du et al. 2012; Hibbett 2001; O'Donnell et al. 2011; Qin et al. 2018) or the North Atlantic Land Bridge (Du et al. 2012; Skrede et al. 2011) might both have occurred, whereas the most possible dispersal corridor for the exchanges of $P$. pulmonarius ancient populations and Clade IIIb ancient populations could be the Beringia during late Miocene and middle Pliocene (Chen et al. 2015; Feng et al. 2012; Han et al. 2018). Subsequent vicariance events, such as the opening of the Bering Strait, and the disappearance of the North Atlantic Land Bridge would have acted to restrict gene flow and consequently leading to genetic diversification of the $P$. ostreatus species complex in the Old World and the New World.

The intercontinental distribution of $P$. pulmonarius siblings from East Asia, Europe, Africa and North America were indicative of dispersal before the formation of geographical barriers. After originating in East Asia, the divergence of $P$. pulmonarius siblings occurred relatively recently, and the first migration event from East Asia into Europe through Central Asia may have occurred in the late Miocene (8 Ma, node 31; Fig. 3a, b; Table 3). Eurasia was inferred to be the ancestral area for the 
African Pleurotus sp. 7 in our study (7 Ma, node 33; Fig. 3a, b; Table 3). Although multiple hypotheses might account for the spread of ancestral fungal lineage between Africa and Eurasia (Conti et al. 2002; Kosuch et al. 2001; Schatz 1996; Yuan et al. 2005; Zhou et al. 2012), according to the detail of the relative dispersal probability in ancestor area analysis (node 33; Fig. 3a, b), a pathway into Africa from southern Europe or Ancient Mediterranean - Central Asia in the late Miocene, is both plausible and parsimonious (Carranza and Arnold 2004; Guillaumet et al. 2006; Rögl 1997; Wolfart 1987). Together with the dramatic weakening of the African summer monsoon by the Tethys Sea shrinkage during the Tortonian, the arid and desert conditions of the Sahara constituted a strong barrier to gene flow and ultimately, adaption to novel habitats and divergence in allopatry may have occurred from that time on in the $P$. pulmonarius siblings (Boratynski et al. 2012; Brito et al. 2014; Dobigny et al. 2005; Zhang et al. 2014). During the late Miocene (7 Ma, node 32; Fig. 3a, b; Table 3), a migration event from East Asia to North America might have occurred via Beringia as mentioned above, and formed an ancient range throughout the Northern Hemisphere. Subsequently, allopatric divergence may have arisen along with the intermittent disappearance of Beringia (Cai et al. 2014; Manos and Stanford 2001). Consequently, the distribution patterns of $P$. pulmonarius sibling species have gradually established in the Northern Hemisphere and Africa due to fragmentation of the ancient range.

Results from this study show strong patterns of geographical division within the saprotrophic $P$. ostreatus species complex, but occasional long-distance dispersal (LDD) events, shaping the geographical distribution of the extant $P$. ostreatus species complex between East Asia and South America also seemed to occur (node 29; Fig. 3a, b; Table 3). Although oceans are effective barriers to gene exchange, long distance dispersal of fungi prior to anthropogenic influences could potentially entail transoceanic dissemination of basidiospores by wind (Hibbett 2001; Hosaka et al. 2008; Ingold 1971; Liang et al. 2004; Matheny et al. 2009; Moncalvo and Buchanan 2008; Pady and Kapica 1955; Skrede et al. 2011). The role of long-distance dispersal has also been invoked to explain the current distributions of other groups of taxa in Pleurotus (Bresinsky et al. 1987; Zervakis et al. 2004; Zervakis and Venturella 1998). Meanwhile, sporetrapping has demonstrated that spores of certain species of the P. ostreatus complex may be 'trapped' even in areas outside of their known distributions (Vilgalys and Sun 1994a). In addition, a previous study confirmed that species of Pleurotus subgenus Coremiopleurotus produce basidiospores with a particular physiology of dormancy, which can withstand adverse environmental conditions over long distances and germinate only at relatively high temperatures and in the presence of suitable substrates (Lahouvaris et al. 1995; Zervakis et al. 2004). These suggest that the distribution of the $P$. ostreatus species complex is probably not limited by the ability to disperse over long distances. However, there was a possibility cannot be excluded, which the earlier migration from East Asia to North America via the North Atlantic Land Bridge or the Beringia as well as to South America until closing of the Isthmus of Panama during 3.5 Ma (29 Ma, node 29; Fig. 3a, b; Table 3).

\section{Evolution and speciation triggered by climatic change and substrate specificity}

Speciation and development of species richness appear to have been facilitated by climatic factors. At the boundary of the Eocene and the Oligocene (about 33 $\mathrm{Ma}$ ), the rapid drop in temperature may have stimulated the radiation of cold-adapted groups in fungi, such as Amanita, Boletus as well as Cudonia and Spathularia (Feng et al. 2012; Ge et al. 2014; Geml et al. 2006). Our estimation of the initial diversification of the $P$. ostreatus species complex was consistent with this climate change pattern (node 27; Fig. 3a; Table 3), and suggests that the global cooling may have triggered evolutionary radiations of the P. ostreatus species complex in the Northern Hemisphere. This may explain why some extant species of $P$. ostreatus complex, such as $P$. abieticola, $P$. ostreatus, $P$. placentodes, and $P$. pulmonarius, possess coldadapted features (Bresinsky et al. 1987; Liu et al. 2015, 2016; Vilgalys et al. 1993). Cases of very recent radiation offer opportunities to examine the role that palaeoclimatic factors play in speciation (Du et al. 2016; Hewitt 1996, 2000; Klicka and Zink 1999). Examination of the speciation pattern of Clade IIId, suggested that this group was influenced by the Quaternary climatic oscillations and associated environmental changes in Europe between the glacial and interglacial phases (Gómez and Lunt 2007; Hewitt 1996, 1999, 2000, 2004; Qiu et al. 2011; Zervakis et al. 2001, 2014). Therefore, the richness of cold-tolerant species and variety taxonomic levels of Clade IIId in Europe may have accumulated over several Ice Ages (Hewitt 1999; Svenning 2003). Likewise, the stronger cold tolerance of species in Clade IIId might have contributed to its survival during the Pliocene and the Quaternary Ice Age, which probably explains why many species need low temperatures for fruitbody formation (Hua et al. 2017, 2018; Lu et al. 2015).

A terrestrial shift towards dryer condition occurred concurrently along the northern rim of the Mediterranean and Central Asia, where the herbs better suited for drier conditions proliferated due to the uplift of the $\mathrm{Ti}$ betan Plateau, the retreat of the Tethys Sea and ongoing global cooling during the Late Miocene (Liu et al. 2014; Lu et al. 2010; van Dam 2006). In many extant plant 
species, adaptation to dry condition is known to be the main driving force of diversification and rapid radiations (Fiz et al. 2002; Ogburn and Edwards 2015; Verboom et al. 2004). Similarly, it is probable that the continued intensification of aridity in the Plio-Pleistocene had a significant influence on diversification within Clade IIId. In addition, ancestral area reconstruction analysis indicated that a single colonization event took place within P. eryngii var. ferulae from Europe back to northwestern China during the Quaternary (node 46; Fig. 3a, b). Distance isolation and allopatric divergence have been proposed to address the differentiation of the two populations in previous research (Zhao et al. 2016a). It is of note that the two populations from the northwestern China and Mediterranean regions inhabited distinct climatic environments, dominated by temperate steppe with a temperate grassy climate, and by garigue, wasteland and pasture with a subtropical Mediterranean climate, respectively (Chen 1986; Zervakis et al. 2014). The differences in climatic traits would be conducive to promote divergence in the individual populations, such as some candidate genes related to stress responses and DNA repair revealing adaptation to the different environments, and the long-term environmental heterogeneity could promote ongoing allopatric divergence in different populations (Dai et al. 2019; Pildain et al. 2009). However, the distribution pattern of $P$. eryngii var. ferulae cannot be excluded for insufficient samplings, which there remained a scattered distribution from Europe to East Asia since the quaternary glaciation.

The close association between fungi and plants is also likely to be an important factor influencing the distribution of fungi (Malloch et al. 1980). Well known as the white-rot SPF, the P. ostreatus species complex exhibits wood-decay properties that cause degradation of components of the substrate plant cell wall (PCW), including lignin, cellulose, and hemicelluloses (Sánchez 2009; Xie et al. 2016). Although belonging to the same complex, substrate specificity or preference for decayed wood is characterized by the $P$. ostreatus species complex taxa: most species of the P. ostreatus complex have been reported on deciduous and coniferous trees, such as Fagaceae, Betulaceae, Salicaceae and Pinaceae (Albertó et al. 2002; Liu et al. 2015, 2016; Petersen and Hughes 1997; Petersen and Krisai-Greilhuber 1996; Vilgalys et al. 1993; Vilgalys and Sun 1994b), whereas species in Clade IIId grow in association with plant roots or stems of Apiaceae (Eryngium, Ferula, Ferulago, Cachrys, Laserpitium, Diplotaenia and Elaeoselinum) (Boisselier-Dubayle 1983; Bresinsky et al. 1987; Hilber 1982; Joly et al. 1990; Mou et al. 1987; Venturella 2000, 2002; Venturella et al. 2016; Zervakis et al. 2014; Zervakis and Venturella 1998; Zhang et al. 2006; Zhao et al. 2016a, 2016b). Association with coniferous or deciduous logs appeared to be an ancestral character in the P. ostreatus species complex, followed by transitions to stems or roots of herbaceous Apiaceae. Recently, the genomic data provided insights into genomic basis of lignocellulose degradation mechanisms between $P$. ostreatus and $P$. eryngii (Xie et al. 2016; Yang et al. 2016; Zhang et al. 2018). Furthermore, it has been inferred that the substrate plants may have had an effect on the genetic differentiation among the species in Clade IIId due to competition for ecological niches (Zervakis et al. 2014).

\section{CONCLUSION}

With samples of the P. ostreatus species complex from East Asia, Europe, North and South America, and Africa, a robust phylogeny of the $P$. ostreatus species complex was presented based on 1759 newly generated sequences of 40 nuclear single-copy orthologous genes, with a full resolution of the relationships of the major clades and the species. Here, The P. ostreatus species complex was strongly supported as monophyletic, including three major clades and seven subclades. Twenty phylogenetic species were recognized based on genealogical concordance phylogenetic species recognition (GCPSR), with seven putatively new species. The biogeographic analyses of the $P$. ostreatus species complex were conducted based on molecular clock estimation and ancestral area reconstruction for the first time. The data suggested that the most recent common ancestor of the $P$. ostreatus species complex diversified in the late Eocene (about 39 $\mathrm{Ma}$ ) in East Asia, and diversification may have been triggered by the uplifts of the Qinghai-Tibet Plateau, the retreat of Tethys and intensification of aridity in the late Miocene, climate cooling events in Quaternary and substrate transitions to Apiaceae.

\section{Supplementary information}

Supplementary information accompanies this paper at https://doi.org/10. 1186/s43008-020-00031-1. Additional file 1: Forward and reverse PCR primers for amplifying a
short fragment of each single-copy gene.

Additional file 2: Reference of Pleurotus and Hohenbuehelia used in this study and their GenBank accession numbers.

Additional file 3: The best nucleotide substitution models used for dating analysis.

Additional file 4: Multiple alignment of nucleotide sequences of each single-copy gene in non-Pleurotus species for molecular clock analysis.

Additional file 5: $\mathrm{R}$ Commands to perform the analyses of diversification rates.

Additional file 6: Phylogenetic tree inferred from $\mathrm{ML}$ analysis based on each single-copy gene. Branch support values are indicated by numbers above branches (MLB $\geq 70 \%, B P P \geq 0.95$ ). Taxon labels are listed in Table 1.

Additional file 7: Phylogenetic relationships of Pleurotus inferred from ITS sequences using ML analysis. Branch support values are indicated by 
numbers above branches (MLB $\geq 70 \%)$. Accession numbers for sequences retrieved from GenBank database are listed in Additional file 2.

Additional file 8: Average evolutionary divergence over RPB2 sequences pairs within and between groups (provincially adopted phylogenetic species) calculated by MEGA 5 .

Additional file 9: Phylogenetic relationships of the P. ostreatus species complex inferred from RPB2 sequences using $\mathrm{ML}$ analysis. Branch support values are indicated by numbers above branches (MLB $\geq 70 \%$, BPP $\geq$ 0.95). Provisionally adopted names (based on tree topology) are listed. Accession numbers for sequences generated newly and retrieved from GenBank database are listed in Table 1.

Additional file 10: Criteria for phylogenetic species recognized by genealogical concordance in individual gene and in the combined dataset

\section{Abbreviations}

EMF: Ectomycorrhizal fungi; SPF: Saprotrophic fungi; NGS: Next-generation sequencing; HKAS: Herbarium of Cryptogams, Kunming Institute of Botany of the Chinese Academy of Sciences; CCMSSC: China Center for Mushroom Spawn Standards and Control; ACAM: Herbarium of the Laboratory of the General and Agricultural University of Athens; CBS: Westerdijk Fungal Biodiversity Institute; CTAB: Cetyltrimethyl ammonium bromide; ITS: Internal transcribed spacer region; RPB2: The gene for RNA polymerase ॥ second largest subunit; ML: Maximum likelihood; GCPSR: Genealogical concordance phylogenetic species recognition; MCC: Maximum clade credibility; LTT: Lineages through time; HHM: Himalayan and Hengduan Mountains region; QTP: Qinghai-Tibet Plateau; BLB (Beringia): Bering Land Bridge; NALB: North Atlantic Land Bridge; LDD: Long-distance dispersal events; PCW: Plant cell wall

\section{Acknowledgements}

The authors thank the curators of the culture collections of CCMSSC, ACAM and CBS; Institute of Microbiology, Beijing Forestry University; and G.I. Zervakis, Ping Zhang, Zai-Wei Ge, Bang Feng, Qi Zhao, Kuan Zhao, Gang Wu, Jiao Qin, and Jian-Wei Liu for providing specimens. They owe thanks to JianJun Jin and Lu Sun, who provided assistance of R language in the bioinformatics analysis.

\section{Adherence to national and international regulations}

Not applicable.

\section{Authors' contributions}

Zhu L. Yang and Jing Li designed the research. Xiao-Bin Liu collected materials. Jing Li performed experiments, analyzed data and wrote the manuscript. Zhu L. Yang, Li-Hong Han and Zhi-Wei Zhao revised the manuscript. The authors read and approved the final manuscript.

\section{Funding}

Financial support was provided by the Strategic Priority Research Program of Chinese Academy of Sciences (XDB31000000), the Second Tibetan Plateau Scientific Expedition and Research (STEP) Program (Grant No. 2019QZKK0503),the National Nature Science Foundation of China (31860005) and Yunnan Ten-Thousand-Talents Plan - Yunling Scholar Project.

\section{Availability of data and materials}

All data generated or analyzed during this study are included in this published article [and its supplementary information files].

\section{Ethics approval and consent to participate} Not applicable.

\section{Consent for publication}

Not applicable.

\section{Competing interests}

The authors declare that they have no competing interests.

\section{Author details}

'CAS Key Laboratory for Plant Diversity and Biogeography of East Asia, Kunming Institute of Botany, Chinese Academy of Science, Kunming 650201, Yunnan, China. ${ }^{2}$ Yunnan Key Laboratory for Fungal Diversity and Green Development, Kunming 650201, Yunnan, China. ${ }^{3}$ State Key Laboratory of Conservation and Utilization for Bioresources in Yunnan, Yunnan University, Kunming 650091, Yunnan, China. ${ }^{4}$ College of Biological Resource and Food Engineering, Qujing Normal University, Qujing 655011, Yunnan, China.

Received: 13 December 2019 Accepted: 31 March 2020

Published online: 08 June 2020

\section{References}

Al-Tanlimi S, Charleston MA, Clayton DH, Demastes JW, Gray RD et al (2003) Tangled trees: phylogeny, cospeciation, and coevolution. University of Chicago Press, Chicago

Akaike $H$ (1981) Likelihood of a model and information criteria. Journal of Econometrics 16:3-14 https://doi.org/10.1016/0304-4076(81)90071-3

Albertó EO, Petersen RH, Hughes KW, Lechner B (2002) Miscellaneous notes on Pleurotus. Persoonia 18:55-69

Austin AT, Yahdjian L, Stark JM, Belnap J, Porporato A et al (2004) Water pulses and biogeochemical cycles in arid and semiarid ecosystems. Oecologia 141: 221-235 https://doi.org/10.1007/s00442-004-1519-1

Avin FA, Bhassu S, Tan YS, Shahbazi P, Vikineswary S (2014) Molecular divergence and species delimitation of the cultivated oyster mushrooms: integration of IGS1 and ITS. The Scientific World Journal 10:793414 https://doi.org/10.1155/ 2014/793414

Baker PW, Charlton A, Hale MDC (2018) Fibre degradation of wheat straw by Pleurotus eryngii under low moisture conditions during solid-state fermentation. Letters in Applied Microbiology 68:182-187 https://doi.org/10. 1111/lam.13104

Bao DP, Ishihara H, Mori N, Kitamoto Y (2004) Phylogenetic analysis of oyster mushrooms ( Pleurotus spp.) based on restriction fragment length polymorphisms of the 5' portion of $26 \mathrm{~S}$ rDNA. Journal of Wood Science 50 169-176 https://doi.org/10.1007/s10086-003-0539-5

Berbee ML, Taylor JW (2010) Dating the molecular clock in fungi-how close are we? Fungal Biology Reviews 24:1-16 https://doi.org/10.1016/j.fbr.2010.03.001

Binder M, Justo A, Riley R, Salamov A, Lopez-Giraldez F et al (2013) Phylogenetic and phylogenomic overview of the Polyporales. Mycologia 105:1350-1373 https://doi.org/10.3852/13-003

Boisselier-Dubayle MC (1983) Taxonomic significance of enzyme polymorphism among isolates of Pleurotus (Basidiomycetes) from umbellifers. Transactions of the British Mycological Society 81:121-127 https://doi.org/10.1016/S00071536(83)80211-3

Boratynski Z, Brito JC, Mappes T (2012) The origin of two cryptic species of African desert jerboas (Dipodidae: Jaculus). Biological Journal of the Linnean Society 105:435-445 https://doi.org/10.1111/j.1095-8312.2011.01791.x

Bresinsky A, Fischer M, Meixner B, Paulus W (1987) Speciation in Pleurotus. Mycologia 79:234-245 https://doi.org/10.1080/00275514.1987.12025703

Brito JC, Godinho R, Martínez-Freiría F, Pleguezuelos JM, Rebelo H et al (2014) Unravelling biodiversity, evolution and threats to conservation in the SaharaSahel. Biological Reviews of the Cambridge Philosophical Society 89:215-231 https://doi.org/10.1111/brv.12049

Brock CD, Harmon $\sqcup$, Alfaro ME (2011) Testing for temporal variation in diversification rates when sampling is incomplete and nonrandom. Systematic Biology 60:410-419 https://doi.org/10.1093/sysbio/syr007

Cai Q, Tulloss RE, Tang LP, Tolgor B, Zhang P, Chen ZH, Yang ZL (2014) Multilocus phylogeny of lethal amanitas: implications for species diversity and historical biogeography. BMC Evolutionary Biology 14:143 https://doi.org/10. 1186/1471-2148-14-143

Cardwell G, Bornman JF, James AP, Black $\amalg$ (2018) A review of mushrooms as a potential source of dietary vitamin D. Nutrients 10:1498 https://doi.org/10. 3390/nu10101498

Carlsen T, Engh IB, Decock C, Rajchenberg M, Kauserud H (2011) Multiple cryptic species with divergent substrate affinities in the Serpula himantioides species complex. Fungal Biology 115:54-61 https://doi.org/10.1016/j.funbio.2010.10.004

Carranza S, Arnold EN (2004) History of West Mediterranean newts, Pleurodeles (Amphibia: Salamandridae) inferred from old and recent DNA sequences. Systematics and Biodiversity 1:327-337 https://doi.org/10.1017/ S1477200003001221 
Castresana J (2000) Selection of conserved blocks from multiple alignments for their use in phylogenetic analysis. Molecular Biology and Evolution 17:540552 https://doi.org/10.1093/oxfordjournals.molbev.a026334

Chen JJ, Cui BK, Zhou LW, Korhonen K, Dai YC (2015) Phylogeny, divergence time estimation, and biogeography of the genus Heterobasidion (Basidiomycota, Russulales). Fungal Diversity 71:185-200 https://doi.org/10.1007/s13225-014$0317-2$

Chen ZC (1986) Preliminary research on the domestication of Pleurotus ferulae. Edible Fungi China 2:16-17 (in Chinese)

Coetzee MPA, Wingfield BD, Harrington TC, Dalevi D, Coutinho TA, Wingfield M. (2000) Geographical diversity of Armillaria mellea s. s. Based on phylogenetic analysis. Mycologia 92:105-113 https://doi.org/10.2307/3761454

Conti E, Eriksson T, Schönenberger J, Sytsma KJ, Baum DA (2002) Early tertiary out-of-India dispersal of Crypteroniaceae: evidence from phylogeny and molecular dating. Evolution 56:1931-1942 https://doi.org/10.1111/j.00143820.2002.tb00119.x

Dai YT, Sun L, Yin XL, Gao M, Zhao YT et al (2019) Pleurotus eryngii genomes reveal evolution and adaptation to the Gobi desert environment. Frontiers in Microbiology 10:2024 https://doi.org/10.3389/fmicb.2019.02024

Dettman JR, Jacobson DJ, Taylor JW (2006) Multilocus sequence data reveal extensive phylogenetic species diversity within the Neurospora discreta complex. Mycologia 98:436-446 https://doi.org/10.1080/15572536.2006. 11832678

Dettman JR, Jacobson DJ, Turner E, Pringle A, Taylor JW (2003) Reproductive isolation and phylogenetic divergence in Neurospora: comparing methods of species recognition in a model eukaryote. Evolution 57:2721-2741 https:// doi.org/10.1554/03-074

Dobigny G, Aniskin V, Granjon L, Cornette R, Volobouev V (2005) Recent radiation in west African Taterillus (Rodentia, Gerbillinae): the concerted role of chromosome and climatic changes. Heredity 95:358-368 https://doi.org/10. 1038/sj.hdy.6800730

Doyle JJ, Doyle JL (1987) A rapid DNA isolation procedure for small quantities of fresh leaf tissue. Phytochemical Bulletin 19:11-15

Drummond AJ, Suchard MA, Xie D, Rambaut A (2012) Bayesian phylogenetics with BEAUti and the BEAST 1.7. Molecular Biology and Evolution 29:19691973 https://doi.org/10.1093/molbev/mss075

Du XH, Zhao Q, O'Donnell K, Rooney AP, Yang ZL (2012) Multigene molecular phylogenetics reveals true morels (Morchella) are especially species-rich in China. Fungal Genetics and Biology 49:455-469 https://doi.org/10.1016/j.fgb. 2012.03.006

Du XH, Zhao Q, Xu JP, Yang ZL (2016) High inbreeding, limited recombination and divergent evolutionary patterns between two sympatric morel species in China. Scientific Reports 6:22434 https://doi.org/10.1038/srep22434

Egan AN, Schlueter J, Spooner DM (2012) Applications of next-generation sequencing in plant biology. American Journal of Botany 99:175-185 https:// doi.org/10.3732/ajb.1200020

Estrada AER, del Mar J-GM, Royse DJ (2010) Pleurotus eryngii species complex: sequence analysis and phylogeny based on partial EF1a and RPB2 genes. Fungal Biology 114:421-428 https://doi.org/10.1016/j.funbio.2010.03.003

Feng B, Xu JP, Wu G, Zeng NK, Li YC et al (2012) DNA sequence analyses reveal abundant diversity, endemism and evidence for Asian origin of the porcini mushrooms. PLoS One 7:e37567 https://doi.org/10.1371/journal.pone. 0037567

Fiz O, Valcárcel V, Vargas P (2002) Phylogenetic position of Mediterranean Asteraceae and character evolution of daisies (Bellis, Asteraceae) inferred from nrDNA ITS sequences. Molecular Phylogenetics and Evolution 25:157171 https://doi.org/10.1016/S1055-7903(02)00228-2

Gao S, Hu P, Bian YB, Zhang JX (2008a) Identification of the three Pleurotus spawns based on ITS sequence. Hubei Agricultural Sciences 47:1390-1393 (in Chinese)

Gao S, Huang CY, Chen Q, Bian YB, Zhang JX (2008b) Phylogenetic relationship of Pleurotus species based on nuclear large subunit ribosomal DNA sequence. Journal of Plant Genetic Resource 9:328-334 (in Chinese)

Ge ZW, Yang ZL, Pfister DH, Carbone M, Bau T, Smith ME (2014) Multigene molecular phylogeny and biogeographic diversification of the earth tongue fungi in the genera Cudonia and Spathularia (Rhytismatales, Ascomycota). PLoS One 9:e103457 https://doi.org/10.1371/journal.pone.0103457

Geml J, Laursen GA, O’Neill KO, Nusbaum HC, Taylor DL (2006) Beringian origins and cryptic speciation events in the fly agaric (Amanita muscaria). Molecular Ecology 15:225-239 https://doi.org/10.1016/S0140-6736(01)87791-6

Geml J, Tulloss RE, Laursen GA, Sazanova NA, Taylor DL (2008) Evidence for strong inter- and intracontinental phylogeographic structure in Amanita muscaria, a wind-dispersed ectomycorrhizal basidiomycete. Molecular Phylogenetics and Evolution 48:694-701 https://doi.org/10.1016/j.ympev. 2008.04.029

Golak-Siwulska I, Ka_użewicz A, Spiżewski T, Siwulski M, Sobieralski K (2018) Bioactive compounds and medicinal properties of oyster mushrooms (Pleuorus sp.). Folia Horticulturae 30:191-201 https://doi.org/10.2478/fhort2018-0012

Graham A (1999) Late cretaceous and Cenozoic history of north American vegetation. Oxford University Press, New York

Grímsson F, Denk T (2005) Fagus from the Miocene of Iceland: systematics and biogeographical considerations. Review of Palaeobotany and Palynology 134: 27-54 https://doi.org/10.1016/j.revpalbo.2004.11.002

Guillaumet A, Pons JM, Godelle B, Crochet PA (2006) History of the crested lark in the Mediterranean region as revealed by mtDNA sequences and morphology. Molecular Phylogenetics and Evolution 39:645-656 https://doi. org/10.1016/j.ympev.2006.01.002

Gómez A, Lunt DH (2007) Refugia within refugia: patterns of phylogeographic concordance in the Iberian Peninsula. In: Weiss S, Ferrand N (eds) Phylogeography of southern European refugia. Springer Netherlands, Berlin

Han LH, Feng B, Wu G, Halling RE, Buyck B et al (2018) African origin and global distribution patterns: evidence inferred from phylogenetic and biogeographical analyses of ectomycorrhizal fungal genus Strobilomyces. Journal of Biogeography 45:201-212 https://doi.org/10.1111/jbi.13094

Harrison TM, Copeland P, Kidd WSF, Yin A (1992) Raising Tibet. Science 255:16631670 https://doi.org/10.2108/zsj.27.487

He XL, Wu B, Li Q, Peng WH, Huang ZQ, Gan BC (2016) Phylogenetic relationship of two popular edible Pleurotus in China, Bailinggu ( $P$. eryngii var. tuoliensis) and Xingbaogu (P. eryngii), determined by ITS, RPB2 and EF1 a sequence. Molecular Biology Reports 43:573-582 https://doi.org/10.1007/s11033-0163982-2

Hewitt GM (1996) Some genetic consequences of ice ages, and their role in divergence and speciation. Biological Journal of the Linnean Society 58:247276 https://doi.org/10.1006/bijl.1996.0035

Hewitt GM (1999) Post-glacial re-colonization of European biota. Biological Journal of the Linnean Society 68:87-112 https://doi.org/10.1006/bijl.1999. 0332

Hewitt GM (2000) The genetic legacy of the quaternary ice ages. Nature 405:907913 https://doi.org/10.1603/AN12033

Hewitt GM (2004) Genetic consequences of climatic oscillations in the quaternary. Philosophical transactions of the Royal Society of London. Series B: Biological Sciences 359:183-195 https://doi.org/10.1098/rstb.2003.1388

Hibbett DS (2001) Shiitake mushrooms and molecular clocks: historical biogeography of Lentinula. Journal of Biogeography 28:231-241 https://doi. org/10.1046/j.1365-2699.2001.00528.x

Hibbett DS, Hansen K, Donoghue MJ (1998) Phylogeny and biogeography of Lentinula inferred from an expanded rDNA dataset. Mycological Research 102:1041-1049 https://doi.org/10.1017/S0953756297005996

Hibbett DS, Matheny PB (2009) The relative ages of ectomycorrhizal mushrooms and their plant hosts estimated using Bayesian relaxed molecular clock analyses. BMC Biology 7:13 https://doi.org/10.1186/1741-7007-7-13

Hilber O (1982) Die Gattung Pleurotus (Fr.) Kummer unter besonderer Berücksichtigung des Pleurotus eryngii-Formenkomplexes. Strauss \& Cramer $\mathrm{GmbH}$, Vaduz

Hosaka K, Castellano MA, Spatafora JW (2008) Biogeography of Hysterangiales (Phallomycetidae, Basidiomycota). Mycological Research 112:448-462 https:// doi.org/10.1016/j.mycres.2007.06.004

Hua S, Qi B, Fu YP, Li Y (2017) DNA methylation changes in Pleurotus eryngii subsp. tuoliensis (Bailinggu) in response to low temperature stress. International Journal of Agriculture and Biology 19:328-334 https://doi.org/ 10.17957/IJAB/15.0286

Hua S, Zhang B, Fu YP, Qi B, Li YS et al (2018) Enzymatic gene expression by Pleurotus tuoliensis (Bailinggu): differential regulation under low temperature induction conditions. World Journal of Microbiology and Biotechnology 34 : 160 https://doi.org/10.1007/s11274-018-2487-7

Ingold CT (1971) Fungal spores: their libération and dispersal. Clarendon Press, Oxford

James TY, Moncalvo JM, Li S, Vilgalys R (2001) Polymorphism at the ribosomal DNA spacers and its relation to breeding structure of the widespread mushroom Schizophyllum commune. Genetics 157:149-161

James TY, Porter D, Hamrick JL, Vilgalys R (1999) Evidence for limited intercontinental gene flow in the cosmopolitan mushroom, Schizophyllum commune. Evolution 53:1665-1677 https://doi.org/10.2307/2640430 
Joly P, Cailleux R, Cerceau MT (1990) La stérilité mâle pathologique, élément de la co-adaptation entre populations de champignons et de plantes-hôtes: modèle des Pleurotes des Ombellifères. Bulletin de la Société Botanique de France 137:71-85 https://doi.org/10.1080/01811789.1990.10827002

Katoh K, Misawa K, Kuma Kl, Miyata T (2002) MAFFT: a novel method for rapid multiple sequence alignment based on fast Fourier transform. Nucleic Acids Research 30:3059-3066 https://doi.org/10.1093/nar/gkf436

Kawai G, Babasaki K, Neda H (2008) Taxonomic position of a Chinese Pleurotus "Bailinggu": it belongs to Pleurotus eryngii (DC.:Fr.) Quél. And evolved independently in China. Mycoscience 49:75-87 https://doi.org/10.1007/ S10267-007-0392-2

Kay E, Vilgalys R (1992) Spatial distribution and genetic relationships among individuals in a natural population of the oyster mushroom Pleurotus ostreatus. Mycologia 84:173-182 https://doi.org/10.2307/3760248

Klicka J, Zink RM (1999) Pleistocene effects on north American songbird evolution. Proceedings of the Royal Society B: Biological Sciences 266:695700 https://doi.org/10.1098/rspb.1999.0691

Kosuch J, Vences M, Dubois A, Ohler A, Böhme W (2001) Out of Asia: mitochondrial DNA evidence for an oriental origin of tiger frogs, genus Hoplobatrachus. Molecular Phylogenetics and Evolution 21:398-407 https:// doi.org/10.1006/mpev.2001.1034

Lahouvaris E, Balis C, Zervakis G (1995) Effect of environmental factors on the germination of Pleurotus cystidiosus basidiospores. Science and Cultivation of Edible Fungi 14:833-841

Lewinsohn D, Nevo E, Wasser SP, Hadar Y, Beharav A (2001) Genetic diversity in populations of the Pleurotus eryngii complex in Israel. Mycological Research 105:941-951 https://doi.org/10.1016/S0953-7562(08)61950-4

Li J, He X, Liu XB, Yang ZL, Zhao ZW (2017) Species clarification of oyster mushrooms in China and their DNA barcoding. Mycological Progress 16:191203 https://doi.org/10.1007/s11557-016-1266-9

Li XL, Yao YJ (2004) Assembling phylogenetic tree of Pleurotus based on $28 \mathrm{~S}$ rDNA sequencing. Mycosystema 23:345-350

Liang Y, Guo LD, Ma KP (2004) Genetic structure of a population of the ectomycorrhizal fungus Russula vinosa in subtropical woodlands in Southwest China. Mycorrhiza 14:235-240 https://doi.org/10.1007/s00572-0030260-7

Lickey EB, Hughes KW, Petersen RH (2002) Biogeographical patterns in Artomyces pyxidatus. Mycologia 94:461-471 https://doi.org/10.1080/15572536.2003. 11833211

Lin CP, Huang JP, Wu CS, Hsu CY, Chaw SM (2010) Comparative chloroplast genomics reveals the evolution of Pinaceae genera and subfamilies. Genome Biology and Evolution 2:504-517 https://doi.org/10.1093/gbe/evq036

Liu WG, Liu ZH, An ZS, Sun JM, Chang H et al (2014) Late Miocene episodic lakes in the arid Tarim Basin, western China. Proceedings of the National Academy of Sciences of the United States of America 111:16292-16296 https://doi.org/ 10.1073/pnas.1410890111

Liu XB, Li J, Horak E, Yang ZL (2016) Pleurotus placentodes, originally described from Sikkim, rediscovered after 164 years. Phytotaxa 267:137-145 https://doi. org/10.11646/phytotaxa.267.2.6

Liu XB, Liu JW, Yang ZL (2015) A new edible mushroom resource, Pleurotus abieticola, in southwestern China. Mycosystema 34:581-588

Lu H, Wang X, Li L (2010) Aeolian sediment evidence that global cooling has driven late Cenozoic stepwise aridification in Central Asia. Geological Society, London, Special Publications 342:29-44 https://doi.org/10.1144/SP342.4

Lu RS, Han ML, Huo XJ, Ma YL, Ma YF et al (2015) Effects of low temperature stimulation on cultivation efficiency of Pleurotus eryngii Quél. Hubei Agricultural Sciences 54:636-639 (in Chinese)

Lücking R, Huhndorf S, Pfister DH, Plata ER, Lumbsch HT (2009) Fungi evolved right on track. Mycologia 101:810-822 https://doi.org/10.3852/09-016

Lumbsch HT, Buchanan PK, May TW, Mueller GM (2008) Phylogeography and biogeography of fungi. Mycological Research 112:423-424 https://doi.org/10. 1016/j.mycres.2008.02.002

Magallón S, Gómez-Acevedo S, Sánchez-Reyes LL, Hernández-Hernández T (2015) A metacalibrated time-tree documents the early rise of flowering plant phylogenetic diversity. New Phytologist 207:437-453 https://doi.org/10.1111/ nph.13264

Magoč T, Salzberg SL (2011) FLASH: fast length adjustment of short reads to improve genome assemblies. Bioinformatics 27:2957-2963 https://doi.org/10. 1093/bioinformatics/btr507

Malloch DW, Pirozynski KA, Raven PH (1980) Ecological and evolutionary significance of mycorrhizal symbioses in vascular plants (a review).
Proceedings of the National Academy of Sciences of the United States of America 77:2113-2118 https://doi.org/10.1073/pnas.77.4.2113

Manos PS, Stanford AM (2001) The historical biogeography of Fagaceae: tracking the tertiary history of temperate and subtropical forests of the northern hemisphere. International Journal of Plant Sciences 162:S77-S93 https://doi. org/10.1086/323280

Matheny PB, Aime MC, Bougher NL, Buyck B, Desjardin DE et al (2009) Out of the Palaeotropics? Historical biogeography and diversification of the cosmopolitan ectomycorrhizal mushroom family Inocybaceae. Journal of Biogeography 36:577-592 https://doi.org/10.1111/j.1365-2699.2008. 02055.x

McCormack JE, Hird SM, Zellmer AJ, Carstens BC, Brumfield RT (2011) Applications of next-generation sequencing to phylogeography and phylogenetics. Molecular Phylogenetics and Evolution 66:526-538 https://doi. org/10.1016/j.ympev.2011.12.007

McGonigle TP (1995) The significance of grazing on fungi in nutrient cycling. Canadian Journal of Botany 73:1370-1376 https://doi.org/10.1139/b95-399

Menolli N Jr, Breternitz BS, Capelari M (2014) The genus Pleurotus in Brazil: a molecular and taxonomic overview. Mycoscience 55:378-389 https://doi.org/ 10.1016/j.myc.2013.12.001

Methven A, Hughes KW, Petersen RH (2000) Flammulina RFLP patterns identify species and show biogeographical patterns within species. Mycologia 92: 1064-1070 https://doi.org/10.2307/3761473

Moncalvo JM, Buchanan PK (2008) Molecular evidence for long distance dispersal across the southern hemisphere in the Ganoderma applanatum - australe species complex (Basidiomycota). Mycological Research 112:425-436 https:// doi.org/10.1016/j.mycres.2007.12.001

Mou CJ, Cao YQ, Ma JL (1987) A new variety of Pleurotus eryngii and its cultural characters. Acta Mycologica Sinica 6:153-156 (in Chinese)

Nagy LG, Walther G, HÁzi J, VÁgvölgyi C, Papp T (2011) Understanding the evolutionary processes of fungal fruiting bodies: correlated evolution and divergence times in the Psathyrellaceae. Systematic Biology 60:303-317 https://doi.org/10.1093/sysbio/syr005

Nylander JAA (2004) MrModeltest v2.2 program distributed by the author. Uppsala University, Uppsala

O'Donnell K, Rooney AP, Mills GL, Kuo M, Weber NS et al (2011) Phylogeny and historical biogeography of the true morels (Merchella) reveals an early cretaceous origin and high continental endemism and provincialism in the Holarctic. Fungal Genetics and Biology 48:252-265 https://doi.org/10.1016/j. fgb.2010.09.006

Ogburn RM, Edwards EJ (2015) Life history lability underlies rapid climate niche evolution in the angiosperm clade Montiaceae. Molecular Phylogenettics and Evolution 92:181-192 https://doi.org/10.1016/j.ympev.2015.06.006

Pady SM, Kapica L (1955) Fungi in air over the Atlantic Ocean. Mycologia 47:3450 https://doi.org/10.1080/00275514.1955.12024427

Paradis E, Claude J, Strimmer K (2004) APE: analyses of phylogenetics and evolution in R language. Bioinformatics 20:289-290 https://doi.org/10.1093/ bioinformatics/btg412

Pegler DN (1977) Pleurotus (Agaricales) in India, Nepal and Pakistan. Kew Bulletin 31:501-510 https://doi.org/10.2307/4119394

Petersen RH, Hughes KW (1993) Intercontinental interbreeding population of Pleurotus pulmonarious, with notes on $P$. ostreatus and other species. Sydowia 45:139-152

Petersen RH, Hughes KW (1997) A new species of Pleurotus. Mycologia 89:173180 https://doi.org/10.2307/3761186

Petersen RH, Krisai-Greilhuber I (1996) An epitype specimen for Pleurotus ostreatus. Mycological Research 100:229-235 https://doi.org/10.1016/S09537562(96)80128-6

Petersen RH, Krisai-Greilhuber I (1999) Type specimen studies in Pleurotus. Persoonia 17:201-219

Pildain MB, Coetzee MPA, Rajchenberg M, Petersen RH, Wingfeld MJ et al (2009) Molecular phylogeny of Armillaria from the Patagonian Andes. Mycological Progress 8:181-194 https://doi.org/10.1007/s11557-009-0590-8

Poore RH (2008) Neogene epeirogeny and the Iceland plume. Dissertation. University of Cambridge, London

Qin J, Horak E, Popa F, Rexer KH, Kost G et al (2018) Species diversity, distribution patterns, and substrate specificity of Strobilurus. Mycologia 110:584-604 https://doi.org/10.1080/00275514.2018.1463064

Qiu YX, Fu CX, Comes HP (2011) Plant molecular phylogeography in China and adjacent regions: tracing the genetic imprints of quaternary climate and environmental change in the world's most diverse temperate flora. Molecular 
Phylogenetics and Evolution 59:225-244 https://doi.org/10.1016/j.ympev. 2011.01.012

R Development Core Team (2014) R: A language and environment for statistical computing. Version 3.1.3. R Foundation for Statistical Computing, Vienna

Rabosky DL (2006) LASER: a maximum likelihood toolkit for detecting temporal shifts in diversification rates from molecular phylogenies. Evolutionary Bioinformatics Online 2:247-250 https://doi.org/10.1177/ 117693430600200024

Rabosky DL (2010) Extinction rates should not be estimated from molecular phylogenies. Evolution 64:1816-1824 https://doi.org/10.1111/j.1558-5646. 2009.00926.x

Rabosky DL, Grundler M, Anderson C, Title P, Shi JJ et al (2014) BAMMtools: an R package for the analysis of evolutionary dynamics on phylogenetic trees. Methods in Ecology and Evolution 5:701-707 https://doi.org/10.1111/2041210X.12199

Rambaut A, Drummond AJ, Xie D, Baele G, Suchard MA (2018) Posterior summarisation in Bayesian phylogenetics using tracer 1.7. Systematic Biology 67:901-904 https://doi.org/10.1093/sysbio/syy032

Ran JH, Wei XX, Wang XQ (2006) Molecular phylogeny and biogeography of Picea (Pinaceae): implications for phylogeographical studies using cytoplasmic haplotypes. Molecular Phylogenetics and Evolution 41:405-419 https://doi.org/10.1016/j.ympev.2006.05.039

Rayner AD, Boddy L (1988) Fungal decomposition of wood. Its biology and ecology. Wiley, Chichester

Renner SS (2005) Relaxed molecular clocks for dating historical plant dispersal events. Trends in Plant Science 10:550-558 https://doi.org/10.1016/j.tplants. 2005.09.010

Rögl F (1997) Palaeogeographic considerations for Mediterranean and Paratethys seaways (Oligocene to Miocene). Annalen des Naturhistorischen Museums Wien 99:279-310

Ronquist F, Teslenko M, van der Mark P, Ayres DL, Darling A et al (2012) MrBayes 3.2: efficient Bayesian phylogenetic inference and model choice across a large model space. Systematic Biology 61:539-542 https://doi.org/10.1093/ sysbio/sys029

Sánchez C (2009) Lignocellulosic residues: biodegradation and bioconversion by fungi. Biotechnology Advances 27:185-194 https://doi.org/10.1016/j. biotechadv.2008.11.001

Sánchez-Ramríez S, Tulloss RE, Amalfi M, Moncalvo JM (2015) Palaeotropical origins, boreotropical distribution and increased rates of diversification in a clade of edible ectomycorrhizal mushrooms (Amanita section Caesareae). Journal of Biogeography 42:351-363 https://doi.org/10.1111/jbi.12402

Sanmartín I, Ronquist F (2004) Southern hemisphere biogeography inferred by event-based models: plant versus animal patterns. Systematic Biology 53: 216-243 https://doi.org/10.1080/10635150490423430

Sato H, Tanabe AS, Toju H (2017) Host shifts enhance diversification of ectomycorrhizal fungi: diversification rate analysis of the ectomycorrhizal fungal genera Strobilomyces and Afroboletus with an 80-gene phylogeny. New Phytologist 214:443-454 https://doi.org/10.1111/nph.14368

Sato H, Toju H (2019) Timing of evolutionary innovation: scenarios of evolutionary diversification in a species-rich fungal clade, Boletales. New Phytologist 222:1924-1935 https://doi.org/10.1111/nph.15698

Schatz GE (1996) Malagasy/indo-Australo-Malesian phytogeographic connections. In: Lourenço WR (ed) Biogeography of Madagascar. Orstom, Paris

Schluter D (2000) The ecology of adaptive radiation. Oxford University Press, New York

Schmit JP, Mueller GM (2007) An estimate of the lower limit of global fungal diversity. Biodiversity and Conservation 16:99-111 https://doi.org/10.1007/ s10531-006-9129-3

Seehausen O, Butlin RK, Keller I, Wagner CE, Boughman LW et al (2014) Genomics and the origin of species. Nature Reviews Genetics 15:176-192 https://doi. org/10.1038/nrg3644

Singer R (1986) The Agaricales in modern taxonomy, 4th edn. Koeltz Scientific Books, Koenigstein

Skrede I, Engh IB, Binder M, Carlsen T, Kauserud H et al (2011) Evolutionary history of Serpulaceae (Basidiomycota): molecular phylogeny, historical biogeography and evidence for a single transition of nutritional mode. BMC Evolutionary Biology 11:230 https://doi.org/10.1186/1471-2148-11-230

Stamatakis A (2006) RAxML-VI-HPC: maximum likelihood-based phylogenetic analyses with thousands of taxa and mixed models. Bioinformatics 22:26882690 https://doi.org/10.1093/bioinformatics/btl446
Svenning JC (2003) Deterministic Plio-Pleistocene extinctions in the European cool-temperate tree flora. Ecology Letters 6:646-653 https://doi.org/10.1046/j. 1461-0248.2003.00477.x

Swofford DL (2003) PAUP*: phylogenetic analysis using parsimony (*and other methods), version 4.0b10. Sinauer associates, Sunderland

Tamura K, Peterson D, Peterson N, Stecher G, Nei M et al (2011) MEGA5: molecular evolutionary genetics analysis using maximum likelihood, evolutionary distance, and maximum parsimony methods. Molecular Biology and Evolution 28:2731-2739 https://doi.org/10.1093/molbev/msr121

Taylor JW, Berbee ML (2006) Dating divergences in the fungal tree of life: review and new analyses. Mycologia 98:838-849 https://doi.org/10.1080/15572536. 2006.11832614

Taylor JW, Turner E, Townsend JP, Dettman JR, Jacobson D (2006) Eukaryotic microbes, species recognition and the geographic limits of species: examples from the kingdom Fungi. Philosophical transactions of the Royal Society of London. Series B: Biological Sciences 361:1947-1963 https://doi.org/10.1098/ rstb.2006.1923

Thiede J, Eldholm O (1983) Speculations about the Paleodepth of the GreenlandScotland ridge during late Mesozoic and Cenozoic times. In: Bott MHP, Saxov S, Talwani M, Thiede J (eds) Structure and development of the GreenlandScotland ridge. Springer, Boston

Thorn RG, Moncalvo JM, Reddy CA, Vilgalys R (2000) Phylogenetic analyses and the distribution of nematophagy support a monophyletic Pleurotaceae within the polyphyletic Pleurotoid-Lentinoid fungi. Mycologia 92:241-252 https://doi.org/10.2307/3761557

Tiffney BH (1985a) Perspectives on the origin of the floristic similarity between eastern Asia and eastern North America. Journal of the Arnold Arboretum 66: 73-94 https://doi.org/10.5962/bhl.part.13179

Tiffney BH (1985b) The Eocene North Atlantic land bridge: its importance in tertiary and modern phytogeography of the northern hemisphere. Journal of the Arnold Arboretum 66:243-273 https://doi.org/10.5962/bhl.part.13183

Tiffney BH, Manchester SR (2001) The use of geological and paleontological evidence in evaluating plant phylogeographic hypotheses in the northern hemisphere tertiary. International Journal of Plant Sciences 162:S3-S17 https://doi.org/10.1086/323880

Truong C, Sánchez-Ramírez S, Kuhar F, Kaplan Z, Smith ME (2017) The Gondwanan connection - southern temperate Amanita lineages and the description of the first sequestrate species from the Americas. Fungal Biology 121:638-651 https://doi.org/10.1016/j.funbio.2017.04.006

Urbanelli S, Della Rosa V, Fanelli C, Fabbri AA, Reverberi M (2003) Genetic diversity and population structure of the Italian fungi belonging to the taxa Pleurotus eryngii (DC.Fr.) Quél. And P. ferulae (DC.Fr.) Quél. Heredity 90:253259 https://doi.org/10.1038/sj.hdy.6800239

van Dam JA (2006) Geographic and temporal patterns in the late Neogene (12-3 $\mathrm{Ma}$ ) aridification of Europe: the use of small mammals as paleoprecipitation proxies. Palaeogeography, Palaeoclimatology, Palaeoecology 238:190-218 https://doi.org/10.1016/j.palaeo.2006.03.025

Venturella G (2000) Typification of Pleurotus nebrodensis. Mycotaxon 75:229-231

Venturella G (2002) On the real identity of Pleurotus nebrodensis in Spain. Mycotaxon 84:445-446

Venturella G, Zervakis Gl, Polemis E, Gargano ML (2016) Taxonomic identity, geographic distribution, and commercial exploitation of the culinarymedicinal mushroom Pleurotus nebrodensis (Basidiomycetes). International Journal of Medicinal Mushrooms 18:59-65 https://doi.org/10.1615/ IntJMedMushrooms.v18.i1.70

Verboom GA, Linder HP, Stock WD (2004) Testing the adaptive nature of radiation: growth form and life history divergence in the African grass genus Ehrharta (Poaceae: Ehrhartoideae). American Journal of Botany 91:1364-1370 https://doi.org/10.3732/ajb.91.9.1364

Vilgalys R, Smith A, Sun BL, Miller OK (1993) Intersterility groups in the Pleurotus ostreatus complex from the continental United States and adjacent Canada. Canadian Journal of Botany 71:113-128 https://doi.org/10.1139/b93-013

Vilgalys R, Sun BL (1994a) Assessment of species distributions in Pleurotus based on trapping of airborne basidiospores. Mycologia 86:270-274 https://doi.org/ 10.1080/00275514.1994.12026407

Vilgalys R, Sun BL (1994b) Ancient and recent patterns of geographic speciation in the oyster mushroom Pleurotus revealed by phylogenetics analysis of ribosomal DNA sequences. Proceedings of the National Academy of Sciences of the United States of America 91:4599-4603 https://doi.org/10.1073/pnas. 91.10.4599 
Wang E, Kirby E, Furlong KP, van Soest M, Xu GQ et al (2012) Two-phase growth of high topography in eastern Tibet during the Cenozoic. Nature Geoscience 5:640-645 https://doi.org/10.1038/ngeo1538

Wen J (1999) Evolution of eastern Asian and eastern north American disjunct distributions in flowering plants. Annual Review of Ecology and Systematics 30:421-455 https://doi.org/10.1600/036364414X680753

Wen J, Ickert-Bond SM (2009) Evolution of the Madrean-Tethyan disjunctions and the north and south American amphitropical disjunctions in plants. Journal of Systematics and Evolution 47:331-348 https://doi.org/10.1111/j.1759-6831. 2009.00054.x

Wiens JJ (2004) Speciation and ecology revisited: phylogenetic niche conservatism and the origin of species. Evolution 58:193-197 https://doi.org/10.1554/03-447

Wilson AW, Binder M, Hibbett DS (2012) Diversity and evolution of ectomycorrhizal host associations in the Sclerodermatineae (Boletales, Basidiomycota). New Phytologist 194:1079-1095 https://doi.org/10.1111/j. 1469-8137.2012.04109.x

Wolfart R (1987) Late cretaceous through quaternary paleogeographic evolution of the Middle East. In: Krupp F, Schneider W, Kinzelbach R (eds) Proceedings of the symposium on Fauna and Zoogeography of the Middle East (Beiheft zum Tubinger atlas des Vorderen orients). Dr. Ludwig Richert Verlag, Wiesbaden

Wolfe BE, Kuo M, Pringle A (2012) Amanita thiersii is a saprotrophic fungus expanding its range in the United States. Mycologia 104:22-33 https://doi. org/10.3852/11-056

Wolfe JA (1978) A paleobotanical interpretation of tertiary climates in the northern hemisphere. American Scientist 66:694-703

Wolfe JA (1997) Relations of environmental change to angiosperm evolution during the late cretaceous and tertiary. In: Iwatsuki K, Raven PH (eds) Evolution and diversification of land plants. Springer-Verlag, Tokyo

Xie CL, Luo W, Li ZM, Yan L, Zhu ZH et al (2016) Secretome analysis of Pleurotus eryngii reveals enzymatic composition for ramie stalk degradation. Electrophoresis 37:310-320 https://doi.org/10.1002/elps.201500312

Yang RH, Li Y, Wang Y, Wan JN, Zhou CL et al (2016) The genome of Pleurotus eryngii provides insights into the mechanisms of wood decay. Journal of Biotechnology 239:65-67 https://doi.org/10.1016/j.jbiotec.2016.10.007

Yang SJ, Dong HL, Lei FM (2009) Phylogeography of regional fauna on the Tibetan plateau: a review. Progress in Natural Science 19:789-799 https://doi. org/10.1016/j.pnsc.2008.10.006

Yang ZL (2005) Diversity and biogeography of higher fungi in China. In: Xu JP (ed) Evolutionary genetics of fungi. Horizon Bioscience, Norfolk

Yi TS, Jin GH, Wen J (2015) Chloroplast capture and intra- and inter-continental biogeographic diversification in the Asian - New World disjunct plant genus Osmorhiza (Apiaceae). Molecular Phylogenetics and Evolution 85:10-21 https://doi.org/10.1016/j.ympev.2014.09.028

Yu XQ, Gao LM, Soltis DE, Soltis PS, Yang JB et al (2017) Insights into the historical assembly of east Asian subtropical evergreen broadleaved forests revealed by the temporal history of the tea family. New Phytologist 215: 1235-1248 https://doi.org/10.1111/nph.14683

Yu Y, Harris AJ, Blair C, He XJ (2015) RASP (reconstruct ancestral state in phylogenies): a tool for historical biogeography. Molecular Phylogenetics and Evolution 87:46-49 https://doi.org/10.1016/j.ympev.2015.03.008

Yuan YM, Wohlhauser S, Möller M, Klackenberg J, Callmander MW et al (2005) Phylogeny and biogeography of Exacum (Gentianaceae): a disjunctive distribution in the Indian Ocean Basin resulted from long distance dispersal and extensive radiation. Systematic Biology 54:21-34 https://doi.org/10.1080/ 10635150590905867

Zachos J, Pagani M, Sloan L, Thomas E, Billups K (2001) Trends, rhythms, and aberrations in global climate $65 \mathrm{Ma}$ to present. Science 292:686-693 https://doi.org/10.1126/science.1059412

Zervakis Gl, Balis C (1996) A pluralistic approach on the study of Pleurotus species, with emphasis on compatibility and physiology of the European morphotaxa. Mycological Research 100:717-731 https://doi.org/10.1016/ S0953-7562(96)80205-X

Zervakis Gl, Labarère J (1992) Taxonomic relationships within the fungal genus Pleurotus as determined by isoeletric focusing analysis of enzyme patterns. Journal of General Microbiology 138:635-645 https://doi.org/10.1099/ 00221287-138-3-635

Zervakis Gl, Moncalvo JM, Vilgalys R (2004) Molecular phylogeny, biogeography and speciation of the mushroom species Pleurotus cystidiosus and allied taxa. Microbiology 150:715-726 https://doi.org/10.1099/mic.0.26673-0

Zervakis Gl, Ntougias S, Gargano ML, Besi MI, Polemis E et al (2014) A reappraisal of the Pleurotus eryngii complex- new species and taxonomic combinations based on the application of a polyphasic approach, and an identification key to Pleurotus taxa associated with Apiaceae plants. Fungal Biology 118:814834 https://doi.org/10.1016/j.funbio.2014.07.001

Zervakis Gl, Venturella G (1998) Towards the elucidation of the systematics of the Pleurotus taxa growing on Umbellifers. In: Proceedings of the 6th international mycological congress, p 7

Zervakis Gl, Venturella G, Papadopoulou K (2001) Genetic polymorphism and taxonomic infrastructure of the Pleurotus eryngii species complex as determined by RAPD analysis, isozyme profiles and ecomorphological characters. Microbiology 147:3183-3194 https://doi.org/10.1099/00221287147-11-3183

Zhang JX, Huang CY, Ng TB, Wang HX (2006) Genetic polymorphism of ferula mushroom grown on Ferula sinkiangensis. Applied Microbiology and Biotechnology 71:304-309 https://doi.org/10.1007/s00253-005-0139-y

Zhang ZB, Wen JW, Li JZ, Ma XT, Yu YN et al (2018) The evolution of genomic and epigenomic features in two Pleurotus fungi. Scientific Reports 8:8313 https://doi.org/10.1038/s41598-018-26619-7

Zhang ZS, Ramstein G, Schuster M, Li C, Contoux C et al (2014) Aridification of the Sahara desert caused by Tethys Sea shrinkage during the Late Miocene Nature 513:401-404 https://doi.org/10.1038/nature13705

Zhao MR, Huang CY, Wu XL, Chen Q, Qu JB et al (2016a) Genetic variation and population structure of the mushroom Pleurotus ferulae in China inferred from nuclear DNA analysis. Journal of Integrative Agriculture 15:2237-2246 https://doi.org/10.1016/S2095-3119(16)61383-7

Zhao MR, Zhang JX, Chen Q, Wu XL, Gao W et al (2016b) The famous cultivated mushroom Bailingqu is a separate species of the Pleurotus eryngii species complex. Scientific Reports 6:33066 https://doi.org/10.1038/srep33066

Zheng HB, Ma ZG, Lü ZZ, Yu ZH (2006) Identification and evaluation of main cultivated species of Pleurotus in China based on ITS sequence analysis. Mycosystema 25:398-407 (in Chinese)

Zhou LL, Su YCF, Thomas DC, Saunders RMK (2012) 'Out-of-Africa' dispersal of tropical floras during the Miocene climatic optimum: evidence from Uvaria (Annonaceae). Journal of Biogeography 39:322-335 https://doi.org/10.1111/j. 1365-2699.2011.02598.x

\section{Publisher's Note}

Springer Nature remains neutral with regard to jurisdictional claims in published maps and institutional affiliations.

Ready to submit your research? Choose BMC and benefit from

- fast, convenient online submission

- thorough peer review by experienced researchers in your field

- rapid publication on acceptance

- support for research data, including large and complex data types

- gold Open Access which fosters wider collaboration and increased citations

- maximum visibility for your research: over $100 \mathrm{M}$ website views per year

At $\mathrm{BMC}$, research is always in progress.

Learn more biomedcentral.com/submission 